ISSN: 0514-7336 — ISSN electrónico: 2386-3943

DOI: https://doi.org/10.14201/zephyrus20218783104

\title{
EL USO DE ESTERAS VEGETALES COMO MATERIAL CONSTRUCTIVO: EVIDENCIAS EN EL SURESTE DE LA PENÍNSULA IBÉRICA DURANTE LA PREHISTORIA RECIENTE
}

\section{The Use of Vegetal Mats as a Building Material: Evidence from the Southeast of the Iberian Peninsula during the Late Prehistory}

\author{
María Pastor Quiles \\ Institut Català d'Arqueologia Clàssica (ICAC). Plaça d'en Rovellat, s/n. 43003 Tarragona. Correo-e: mpastor@icac. \\ cat. ORCID ID: https://orcid.org/0000-0001-6112-6422
}

Recepción: 9/06/2020; Revisión: 10/07/2020; Aceptación: 27/01/2021

\begin{abstract}
Resumen: En este artículo presentamos diversas evidencias arqueológicas de un aspecto de las prácticas arquitectónicas no abordado hasta ahora en la investigación acerca de la Prehistoria Reciente de la Península Ibérica y muy poco conocido en general: el empleo de esteras vegetales integradas en las edificaciones como un material constructivo más. Estas proceden de distintos yacimientos prehistóricos del SE peninsular y han sido obtenidas a partir del estudio de fragmentos constructivos de barro endurecido. Las principales evidencias proceden del núcleo calcolítico de Les Moreres (Crevillente, Alicante), a lo que se unen los indicios pertenecientes a otros cinco enclaves, el neolítico de Los Limoneros ir (Elche, Alicante) y los de la Edad del Bronce de Caramoro I (Elche, Alicante), Cabezo del Polovar y Terlinques (Villena, Alicante), así como la Lloma de Betxí (Paterna, Valencia). Dichos hallazgos ponen de manifiesto el gran potencial informativo de este tipo de materialidad y la necesidad de ampliar el abanico de los elementos considerados como susceptibles de ser utilizados para construir desde cronologías prehistóricas.

Palabras clave: Mediterráneo occidental; Edad de los Metales; arquitectura; esterería; cestería; impronta; fragmentos de barro endurecido.
\end{abstract}

АвSTRACT: In this paper we present diverse archaeological evidence of a building aspect that has not been addressed up to now by the research on the Late Prehistory of the Iberian Peninsula and little known in general: the use of vegetal woven mats integrated in structures as just another construction material. These have been recovered from various prehistoric sites from the Southeast of the Iberian Peninsula through the study of daub fragments. The main evidence comes from the chalcolithic site of Les Moreres (Crevillente, Alicante), along with other signs coming from five enclaves, the Neolithic site of Los Limoneros II (Elche, Alicante) and those of the Bronze Age Caramoro I (Elche, Alicante), Cabezo del Polovar and Terlinques (Villena, Alicante), as well as Lloma de Betxí (Paterna, Valencia). Those findings highlight the highly informative potential of hardened mud pieces and the necessity of considering more elements as prospective building materials from Prehistoric dates.

Key words: Western Mediterranean; Metal Age; Matting; Architecture; Basketry; Imprint; Daub Fragments.

Ediciones Universidad de Salamanca / @@®

Zephyrus, LXXXVII, enero-junio 2021, 83-104 


\section{Introducción ${ }^{1}$}

Diversos estudios han recogido la presencia de esteras y de sus improntas en contextos y materiales arqueológicos de la Prehistoria y la Protohistoria de la Península Ibérica (Alfaro, 1980, 1984; Papí, 1992-1994; Rovira, 2006; Moralejo et al., 2015, entre otros), aunque el empleo como material de construcción de estas superficies vegetales entretejidas no ha sido planteado en estos trabajos de investigación.

Cuando se aborda el uso de fibras vegetales, como el esparto, en las edificaciones de la Prehistoria Reciente peninsular, se hace referencia a las evidencias arqueológicas de cordaje (De Pedro, 1990: 339; Contreras, 2009: 53; Jover y López Padilla, 2013: 157-158) y también a su documentación mediante la impronta negativa de estas cuerdas en restos de barro endurecido (Ayala y Jiménez, 2007; Hernández et al., 2016: 34; Belmonte et al., 2017: 243). En contextos arqueológicos también se documentan improntas de fibras vegetales formando esteras y otras que responderían al empleo de estas en los espacios domésticos, pero no por haber sido integradas en el interior de las partes constructivas, como los alzados o las cubiertas, sino al ser utilizadas para cubrir los suelos de tierra, al igual que se ha documentado en trabajos etnoarqueológicos (Kramer, 1982: 119; Kelly et al., 2005: 404) y arqueológicos (Wendrich, 2005; Cameron, 2017), en yacimientos como Abu Salabikh en Al-Qādisiyyah, Irak (Matthews, 1995: 60), y Jarmo en Kirkūk, Iraq, o Jani en Kermanshah, Irán, en los montes Zagros (Matthews, 2012: 204, 206). Estas improntas de esteras pueden deberse asimismo a su uso en estructuras inmuebles de equipamiento doméstico construidas con barro, como en el caso de las huellas de esteras de esparto trenzado documentadas sobre bancos del Departamento xxviI del asentamiento de la Edad del Bronce de Cabezo Redondo en Villena, Alicante (Hernández et al., 2016: 61).

1 La autora es beneficiaria de un contrato postdoctoral Juan de la Cierva-Formación (FJC2019-039469-I) concedido por el Ministerio de Ciencia e Innovación.
El uso de las esteras como material constructivo es una práctica mayoritariamente desconocida para la bibliografía arqueológica y poco abordada desde un punto de vista general en los estudios de arquitectura o etnografía, aunque documentada en variados ámbitos temporales y geográficos, como se detallará más adelante.

En este artículo presentamos diversas evidencias arqueológicas del empleo durante la Prehistoria Reciente en el SE de la Península Ibérica de esteras fabricadas con elementos vegetales que fueron utilizadas como material de construcción, formando parte de las edificaciones y contribuyendo a conformarlas, combinadas con otros materiales, como las cañas o varas y, sobre todo, la tierra. Es a partir del abundante empleo del barro en las edificaciones de la Prehistoria Reciente peninsular y de la conservación de improntas negativas en restos constructivos, que podemos disponer de las pruebas e indicios del uso para edificar de estas superficies entretejidas de naturaleza orgánica y de difícil preservación en los contextos arqueológicos.

Con este trabajo queremos dar a conocer estas evidencias, presentando las características de estos hallazgos en su contexto arquitectónico. Mediante el mismo esperamos también contribuir a llamar la atención sobre la gran importancia del estudio de los fragmentos constructivos de barro endurecido, como valiosas fuentes de información arqueológica acerca de las formas y prácticas constructivas de los grupos humanos prehistóricos, así como de sus modos de vida. Su potencial informativo permite hacer visible el uso de materiales de construcción apenas planteados, como en este caso. Es por ello que las improntas constructivas de esteras tampoco han sido objeto de atención por parte de los estudios especializados en elementos de barro endurecido.

Los restos materiales que presentamos, en los que se ha podido observar esta función constructiva de las esteras, proceden fundamentalmente del núcleo calcolítico de Les Moreres en Crevillente, Alicante (González Prats, 1983, 1984, 1986; González Prats y Ruiz Segura, 1991-1992), a los que se unen otros indicios pertenecientes a cinco enclaves, el neolítico de Los Limoneros II en Elche, Alicante 
(Barciela et al., 2014; García Atiénzar et al., 2020), y los de la Edad del Bronce de Caramoro I en Elche, Alicante (González Prats y Ruiz Segura, 1995; Jover et al., 2019; Jover et al., 2020); Cabezo del Polovar (Jover et al., 2016) y Terlinques en Villena, Alicante (Jover y López Padilla, 2016), así como la Lloma de Betxí en Paterna, Valencia (De Pedro, 1990, 1998, entre otros) $)^{2}$.

\section{Las esteras en el marco del estudio arqueológico de los materiales constructivos}

Los materiales de construcción identificados en los asentamientos de la Prehistoria Reciente de la Península Ibérica, como en otros territorios, se obtienen a partir de recursos presentes en el entorno natural de los enclaves -tierra, vegetales, madera, piedra-, así como de la reutilización de residuos de las prácticas económicas principales en las que se basaría su subsistencia -paja y estiércol-. A ellos se suma el uso de materiales producidos por estas comunidades, fueran o no fabricados expresa o exclusivamente para construir con ellos y teniendo por lo general aplicaciones diversas. En este grupo de materiales se encuentran los manufacturados con materia vegetal, como cuerdas, cestos y esteras.

Los productos de cordelería, cestería y esterería se han elaborado desde la Prehistoria con diversas especies vegetales -de la caña y el bambú (Kuoni, 1981; Wendrich, 2000: 255; Steen et al., 2003: 136, 147) a las hojas de palmera (Oliver, 1971: 149; 1987; Piqué et al., 2016), pasando por el esparto (De Góngora, 1868; Alfaro, 1980; Papí, 1992-1994; Jover y López Padilla, 2013; Aura et

2 Queremos mostrar nuestro agradecimiento a los directores y directoras de las excavaciones arqueológicas de las que proceden las piezas de barro incluidas en este trabajo, por hacer posible que hayamos podido llevar a cabo su estudio. Gracias de manera especial a A. González Prats, F. J. Jover, M. J. de Pedro, G. García y A. J. Lorrio. Este trabajo ha sido realizado dentro del proyecto "Espacios sociales y espacios de frontera durante el Calcolítico y la Edad del Bronce en el Levante de la Península Ibérica" (HAR2016-76586-P), financiado por el Ministerio de Economía y Competitividad de España. al., 2019)-. El trabajo de estas fibras es común tanto a la producción de cordajes y bienes de cestería como a la de esteras.

$\mathrm{Al}$ igual que ocurre con el resto de materiales constructivos, cuerdas y esteras no solo se habrían empleado en la arquitectura. El uso en actividades constructivas de cordajes y de esteras es un ejemplo de cómo el desarrollo de un mismo proceso artesanal revierte en diferentes aplicaciones, en el ámbito de la edificación y fuera de él. Si bien las cuerdas recuperadas en contextos arqueológicos se asocian en mayor medida a estas aplicaciones arquitectónicas (Bosch et al., 1999: 319; Sánchez Sanz, 2009: 432; Piqué et al., 2018: 269), son otros los usos mejor conocidos de las superficies vegetales entretejidas durante la Prehistoria Reciente peninsular, sobre todo la elaboración de recipientes contenedores o cestos y de otros bienes, como el calzado (Alfaro, 1980; Ayala y Jiménez, 2007; Jover y López Padilla, 2013).

Los productos de esterería, como los de cestería y cordelería, son el fruto de la preparación y disposición de las fibras vegetales con el fin de generar productos de carácter mueble. Asimismo, en el ámbito arquitectónico la materia vegetal se selecciona, prepara y pone en obra de distintas maneras en la conformación de estructuras inmuebles. En este sentido encontramos, entre las llamadas técnicas de construcción mixtas (Proterra, 2003; Knoll et al., 2019), la disposición de elementos vegetales como cańas o varas que, cuando son cubiertos con barro, pasan a entenderse dentro de la técnica constructiva del bajareque (Viñuales et al., 2003; Guerrero, 2007: 195; 2017; Pastor, 2017; 2019: 113; Knoll et al., 2019: 26). Estas cañas o varas que conforman el bajareque pueden aplicarse de distinta forma, en paralelo, cruzadas o entrelazadas. Del mismo modo, en la producción de esteras, cestos y cordaje existen distintas técnicas y tipos de entramados, diferentes modos de disponer las fibras vegetales para obtener así los elementos y superficies deseados. Las principales técnicas de cestería conocidas en la Península Ibérica, que pueden aplicarse a la producción de esteras, son las tramas cordada, tejida, trenzada y en espiral cosida (Kuoni, 1981: 275; Alfaro, 1984). 
La denominación de esteras a las superficies realizadas con vegetales entrelazados o entretejidos se refiere de forma mayoritaria a su empleo para cubrir y aislar el suelo, a modo de alfombras, y que también pueden servir de base y asiento a estructuras de equipamiento doméstico y mobiliario. Estas pueden utilizarse para realizar sobre ellas varias actividades productivas y ello se puede materializar en el registro arqueológico, como sería el caso del secado de la cerámica, que generaría en las piezas aún húmedas impresiones de esteras (Elster, 2003: 246), aunque estas superficies vegetales también se han asociado a la propia producción de dichos recipientes (Papí, 1992-1994: 46; Rovira, 2006, entre otros).

Asimismo, las esteras pueden emplearse para cubrir las techumbres de las edificaciones desde el exterior y contribuir a su protección de los agentes externos, al igual que se usan otras superficies obtenidas de recursos de origen animal, como pieles o lana. También se destinan al cerramiento de vanos o a la delimitación de espacios (Kuoni, 1981: 172, 254; Agorsah, 1985: 105, fig. 2; Van Gijn, 1986: 185, lám. 3), así como a la reparación de partes determinadas de las estructuras (Kelly et al., 2005: 407).

A estos usos ha de sumarse la disposición de las esteras en el interior de las partes de una edificación, como alzados o cubiertas, en combinación con otros materiales de construcción, como la tierra, aplicación que abordamos en este trabajo a partir de diferentes casos documentados para contextos de la Prehistoria Reciente del sE de la Península Ibérica.

\section{El necesario análisis de los restos constructivos de barro en arqueología}

La tierra es uno de los materiales de construcción más utilizados en todo el mundo y se ha empleado para configurar los espacios de residencia, de trabajo y de vida de muchas sociedades, al menos desde el Neolítico, en solitario o combinada con otros materiales constructivos. En los contextos arqueológicos, la construcción con tierra puede quedar materializada a partir de la conservación de restos de barro endurecido, a pesar de que estos elementos de barro no cocido y los materiales orgánicos con los que habitualmente se combina la tierra para construir presentan importantes dificultades de preservación e identificación, conservándose solo de forma excepcional en algunos yacimientos y estando presentes únicamente de forma parcial en otros muchos.

Los fragmentos constructivos de barro endurecido han sido un tipo de materialidad poco conocida y que, con frecuencia, no se ha tenido en la necesaria consideración. Solo de forma minoritaria estos restos materiales son contemplados como fuentes de información por sí mismos y abordados por la investigación, a pesar de que contienen un tipo de datos propio y específico, que no se encuentra en ningún otro componente del registro arqueológico. Así, a las limitaciones propias de la conservación e identificación de estas evidencias se han ido sumando la falta de valoración e interés acerca de estos materiales, junto con las carencias que puedan existir en el conocimiento acerca de estos aspectos constructivos.

Desde la arqueología, estos elementos de barro pueden ser analizados desde una metodología multidisciplinar y basada en su estudio macroscópico (García López y Lara, 1999; Belarte, 1999-2000; De Chazelles, 2003; Gómez Puche, 2004; Knoll y Klamm, 2015; Pastor, 2017, 2019), complementándose con análisis microscópicos, con las aportaciones procedentes de la comparación etnoarqueológica y también mediante la experimentación.

Si bien la metodología de estudio de las evidencias que se presentan en este trabajo está basada fundamentalmente en el análisis macrovisual, en el presente caso son también de vital importancia las referencias etnoarqueológicas, como fuente de hipótesis para un mejor estudio e interpretación de esta materialidad recuperada en contextos prehistóricos con las particularidades mencionadas. Los estudios etnográficos son fundamentales tanto para el conocimiento de la construcción con tierra, como en referencia a los usos tradicionales de fibras vegetales, como el esparto, y a las técnicas cesteras (por ejemplo, Kuoni, 1981). 
El estudio de estos fragmentos permite conocer valiosas cuestiones sobre el empleo de materiales, técnicas y prácticas constructivas. Estos elementos informan, en primer lugar, sobre el empleo de la propia tierra, pero los datos que pueden proporcionar van mucho más allá. Entre otros aspectos, contienen indicios de otros materiales utilizados para edificar, como los de naturaleza orgánica, y de los que en la mayoría de los casos apenas se conservan restos, pero que quedan reflejados en las improntas generadas en los morteros constructivos. En casos como estos, solo el estudio de este tipo de materialidad permite obtener dichos datos, que de otro modo se perderían. Ejemplo de ello son las evidencias que se presentan en este trabajo, proporcionadas por el estudio sistemático de restos de barro endurecido procedentes de seis yacimientos de la Prehistoria Reciente del sE peninsular ${ }^{3}$.

\section{Evidencias del uso constructivo de las esteras en fragmentos de barro de la Prehistoria Reciente del SE peninsular}

El empleo de fibras no entretejidas de esparto incorporadas en las edificaciones se ha señalado en varios asentamientos de la Edad del Bronce del

3 Pastor, M.: La construcción con tierra en la Prehistoria reciente del Levante meridional de la Peninsula Ibérica: materiales, técnicas y procesos constructivos. Tesis doctoral inédita presentada en 2019 en la Univ. de Alicante.

SE, en las techumbres de Terlinques en Villena, Alicante (Jover y López Padilla, 2013: 158), y de Cabezo Gordo o de la Cruz en Totana, Murcia (Ayala, 1989; 2001: 154; Ayala y Jiménez, 2007: 175, fig. 2). El uso de fibras de esparto ha sido planteado también como parte de los revestimientos en alzados, así como en pavimentos, en un marco cronológico posterior, para la ocupación ibérica del asentamiento de la Illeta dels Banyets en El Campello, Alicante (Martínez Carmona et al., 2009: 161; Olcina et al., 2009: 204; Perdiguero, 2016: 53-63).

Además, algunos trabajos han recogido la presencia de improntas de posibles esteras en restos de barro endurecido, pero esta presencia o no ha sido interpretada como resultado de su empleo como material constructivo, o no ha sido objeto de mayor atención. Así, en Coves de Santa Maira en Castell de Castells, Alicante, se han hallado fragmentos de 
barro de cronologías epipaleolíticas con improntas vegetales y evidencias del uso de esta materia como estabilizante de la mezcla de barro, así como fragmentos con negativos de vegetales entretejidos en una cara y superficies alisadas o tratadas en la contraria, pero estos elementos con entramados se interpretan como restos de recipientes (Aura et al., 2020). La impronta de una superficie realizada con fibras entretejidas puede observarse en un resto de barro publicado como fragmento de revestimiento del asentamiento argárico de La Bastida en Totana, Murcia (Lull et al., 2015: 119). Asimismo, en referencia al yacimiento ibérico del Cerro de la Cruz en Almedinilla, Córdoba, se han presentado y estudiado negativos de superficies vegetales con entramado en sarga en restos de barro interpretados como pertenecientes a alzados, cubiertas y forjados de entrepisos (Moralejo et al., 2015: 139). Sin embargo, estas improntas se han asociado a objetos contenedores de cestería relacionados con las funciones de almacenamiento atribuidas a dichos espacios construidos (Moralejo et al., 2015: 141-142).

De este modo, hasta donde tenemos constancia, el uso de esteras como material con el cual edificar no se ha abordado hasta ahora por parte de la investigación para la Prehistoria peninsular.

Como se ha adelantado, el caso de estudio más significativo del que tenemos constancia por el momento para la cuestión que abordamos es el yacimiento calcolítico de Les Moreres, en Crevillente, Alicante. Lo informativo de sus evidencias hace necesario presentarlo en primer lugar, pues estas contribuyen a plantear las hipótesis de interpretación de los materiales de otros asentamientos, uno de ellos más antiguo y el resto posteriores, que se recogen más adelante (Fig. 1).

Durante las intervenciones en Les Moreres, que fue excavado hace varias décadas mediante un sistema de cuadrículas y está datado en la segunda mitad del III milenio a. C., se documentaron los restos de varias edificaciones ovaladas cuyos alzados se construyeron con postes verticales de madera cubiertos con barro (Fig. 2), pero también con zócalos de mampostería (González Prats, 1984, 1986; González Prats y Ruiz Segura, 1991-1992). Durante las intervenciones en este asentamiento se recuperó un numeroso conjunto de elementos de barro

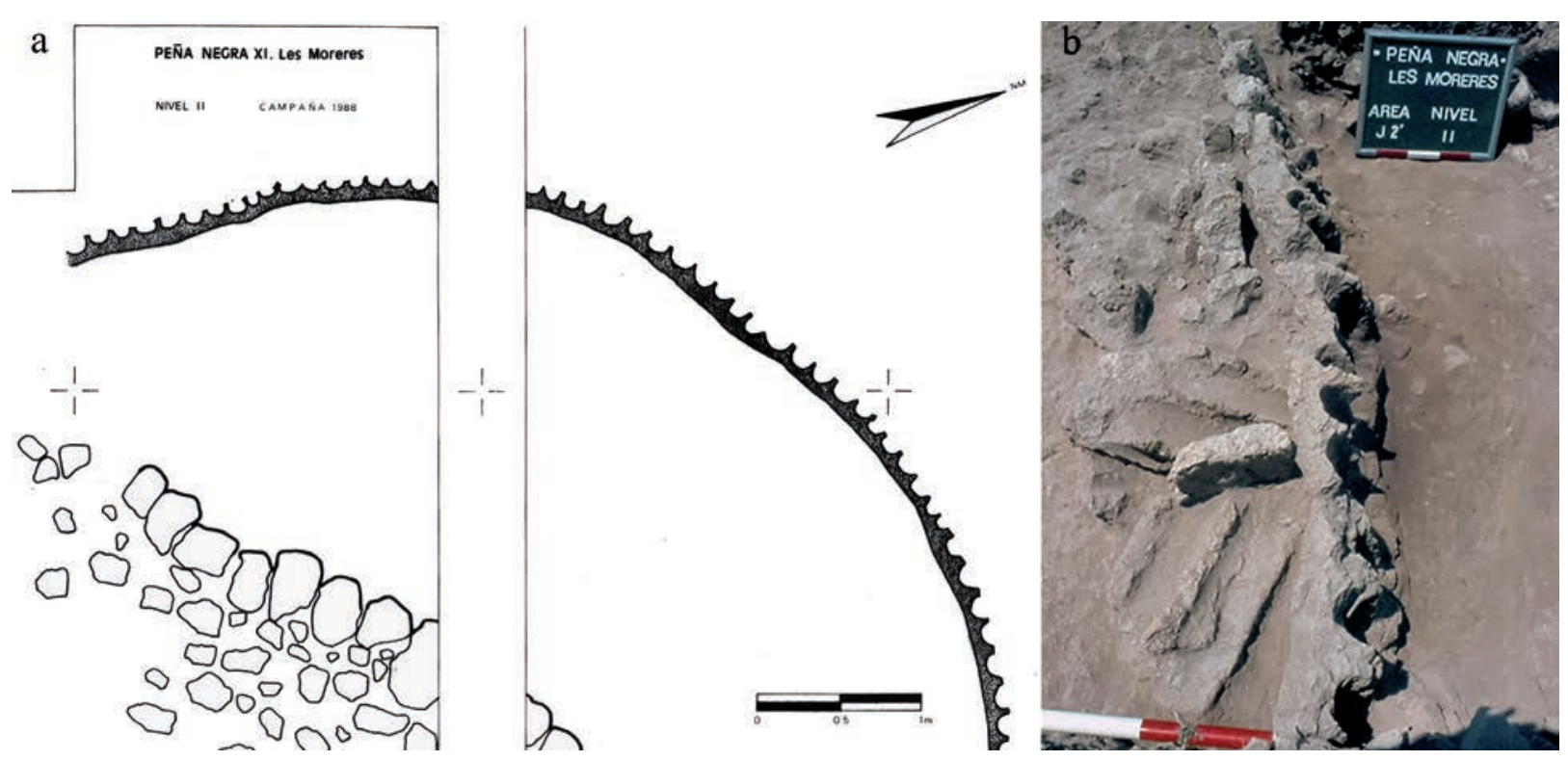

Fig. 2. Estructuras excavadas en Les Moreres, en Crevillente, Alicante: a) plano con alzados de troncos dispuestos en vertical y cubiertos con barro desde el interior; b) imagen de los restos de este alzado, con grandes bloques constructivos de barro caidos hacia el espacio interno de la construcción (fotografias de A. González Prats). 
de enorme interés ${ }^{4}$, con improntas de madera, de sección circular y angular, de cañas y varas, que se combinaron y dispusieron en las partes constructivas de forma paralela, pero también cruzada y entrelazada, unidas con sogas simples y también con cuerdas trenzadas, cubiertas con mortero de barro, atestiguando el empleo de la técnica del bajareque.

Entre los restos constructivos de este asentamiento recuperados entre 1988 y 1993, un número abundante de piezas, un total de 60, muestran la impronta negativa dejada por una superficie vegetal realizada con grupos de tallos paralelos, dispuestos en bandas entretejidas unas con otras perpendicularmente (Fig. 3). Por desgracia, la información contextual de la mayoría de estos materiales no se ha conservado, pero sí disponemos de parte de ella en un grupo de estos fragmentos. Así, proceden de las campañas de excavación de 1990 y, sobre todo, de 1991, concretamente de los cortes $\mathrm{K} 8, \mathrm{~L} 4, \mathrm{M} 7-\mathrm{M} 8, \mathrm{~N} 8-\mathrm{N} 9$ y o7-09, en sus niveles ira y irb, de derrumbe y ocupación.

En buena parte de los fragmentos de barro de Les Moreres con improntas de esteras se puede distinguir que las impresiones de las bandas dispuestas en una de las dos direcciones son más estrechas que las situadas en la otra dirección. Se trataría de esteras realizadas con el entrelazado de tallos, posiblemente de esparto -Stipa tenacissima L.- u otra fibra de morfología similar, que conserva su sección circular

4 Pastor, op. cit. n. 2: 232. de unos pocos milímetros de diámetro, por lo que habría sido utilizado en crudo. El esparto es una especie vegetal abundante hoy en día en el entorno del yacimiento y cuyo trabajo artesanal ha sido de gran importancia en la zona desde hace milenios, como observó Plinio (Hist. Nat., xIx, 26) y hasta cronologías contemporáneas (Cavanilles, 1795: 226; Kuoni, 1981: 255; Belmonte et al., 2017).

Estas impresiones aparecen no en superficies planas, sino superpuestas a diversas improntas negativas de origen constructivo, de disposición paralela (Fig. 3a), en la mayoría de los casos probablemente correspondientes a cañas -Arundo donax-, contando muchos de estos fragmentos con una cara externa de barro regularizado (Fig. 3b). Por ello, podemos inferir que la estera se encontraba junto a 
un panel de cañas y que fue cubierta con barro por su cara exterior, la que no estaría en contacto directo con las cañas. En algún caso de este conjunto de Les Moreres se han documentado estas impresiones de estera sobre improntas de sección circular, pero de diámetro mayor al que habitualmente presentan las cańas, por lo que esta técnica se habría podido emplear también sobre varas o ramas de mayor grosor.

\section{a}
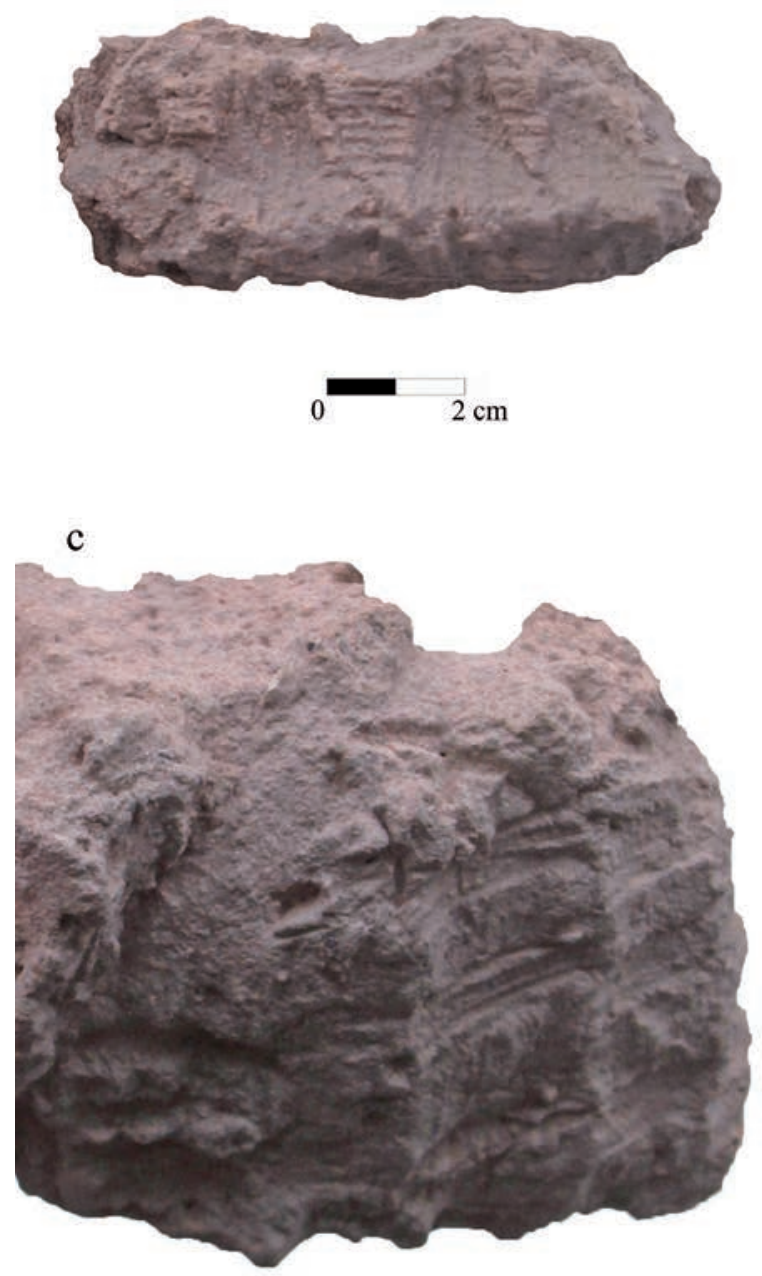

El grado de erosión de las piezas con improntas de esteras de Les Moreres es desigual, pero los rasgos que presentan estos fragmentos son suficientes para observar el entramado, un tipo de trama que sería el mismo en todas las piezas, salvo alguna posible excepción (Fig. 4a), que quizá pueda tener relación con el inicio, el cierre o los extremos de la estera (Elster, 2003: 246, fig. 6.31c; Fajardo et al., 2015, fig. 3). Este entramado (Fig. 5d) ha sido

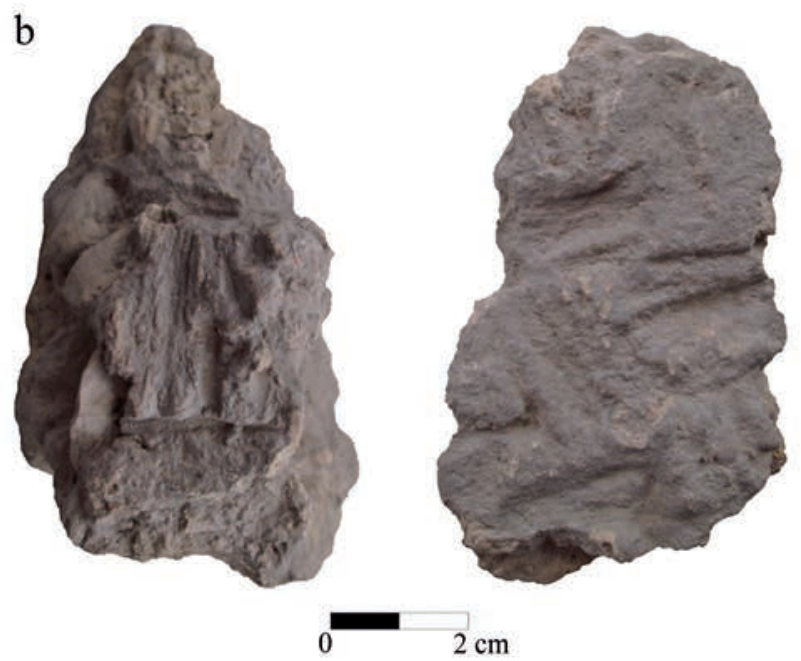

d

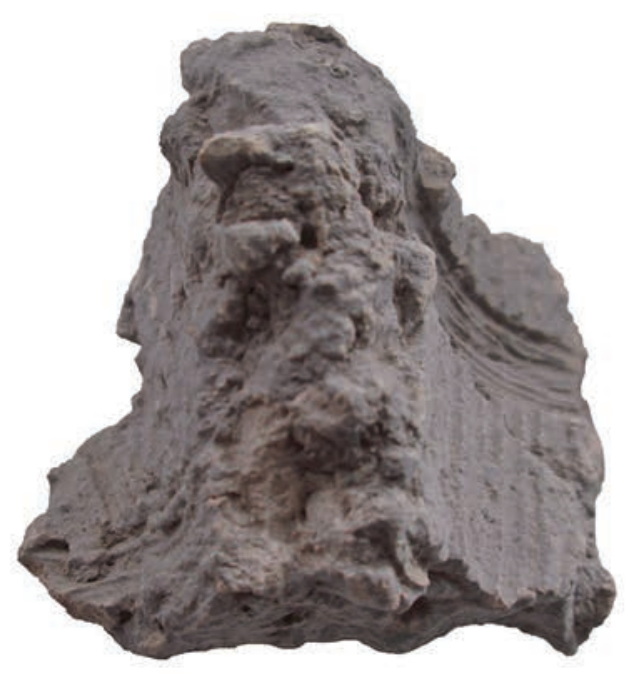

Fig. 4. Impronta de estera de Les Moreres: a) vista lateral de un fragmento con las bandas entrecruzadas que presentan una morfología triangular; b) dos caras de un resto constructivo que cuenta con una impronta de estera en ambas; c) detalle de una de las improntas de este conjunto; d) vista lateral de otro de los restos constructivos con improntas de esteras. 
denominado de tipo liso, plano compuesto o en damero (Alfaro, 1980: 112; 1984: 103, 154; Kuoni, 1981: 281), registrado entre otros tipos en los hallazgos de la Cueva de los Murciélagos en Albuńol, Granada (Alfaro, 1980: 112).

Además, en una de las piezas de Les Moreres se ha conservado la impresión de una superficie de estera en ambas caras del fragmento (Fig. 4b), una de las cuales constituiría una cara interna asociada a una impronta constructiva de sección circular, que podría pertenecer a un panel de cañas. La cara contraria presenta la huella de la estera en una superficie aparentemente plana. Este caso apunta al posible empleo de dos capas de esteras, una adyacente a la estructura de cańas, cubierta a su vez con barro, y la otra añadida a esa capa de barro y hacia el exterior, quizá quedando a la vista. Asimismo, podría tratarse de un pliegue de la estera, en el que el barro hubiera quedado en el interior de ambas superficies.

En un buen número de casos, en los fragmentos con improntas de estera se observa una cara contraria exterior y alisada, incluso distinguiéndose distintas capas de barro superpuestas. En estas piezas, además, la cara alisada presenta con frecuencia huellas paralelas (Fig. 5a) que serían el resultado de su alisado con los dedos de la mano en una misma dirección (Fig. 5c), gesto cuyo resultado habría sido mayoritariamente horizontal. Estas marcas generadas por el alisado de las superficies con los dedos han sido identificadas en otros contextos etnoarqueológicos (Kruger, 2015: 893; Pastor, 2019: 61) y arqueológicos (De Chazelles, 2003: 48; Sherard, 2009: 33; Namdar et al., 2011; Knoll y Klamm, 2015: 90), incluido el conocido yacimiento neolítico de Çatalhöyük en Konya, Turquía (Stevanović, 2013: 105); el asentamiento también neolítico de Piana di Curinga en Calabria, Italia (Shaffer, 1993: 63), o el enclave calcolítico de São Pedro en Évora, Portugal (Bruno et al., 2010: 56). En el ámbito de la Prehistoria Reciente del SE peninsular, se pueden observar en los fragmentos constructivos de asentamientos como Vilches IV en Hellín, Albacete, de cronología calcolítica (García Atiénzar et al., 2016; García Atiénzar y Busquier, 2020); el de la Edad del Bronce argárico de Laderas del Castillo en Callosa de Segura, Alicante (López

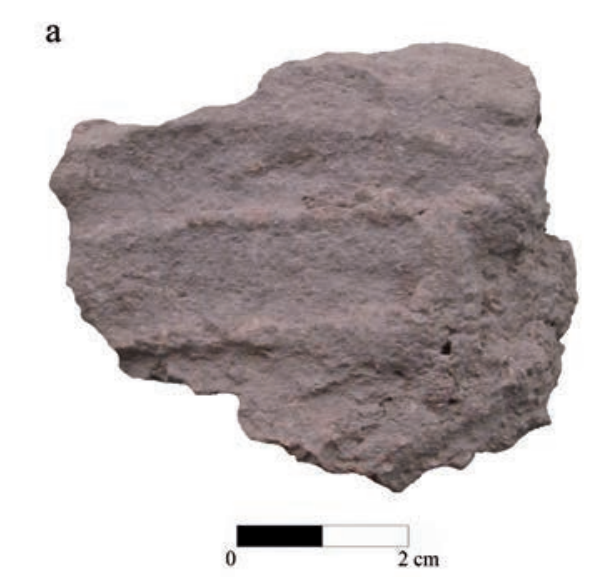

b

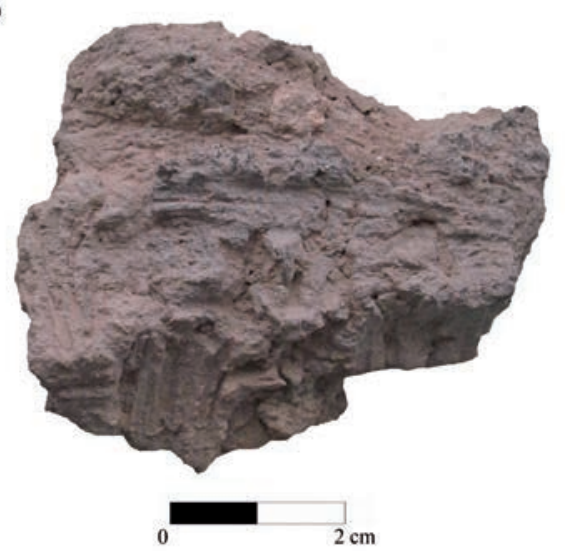

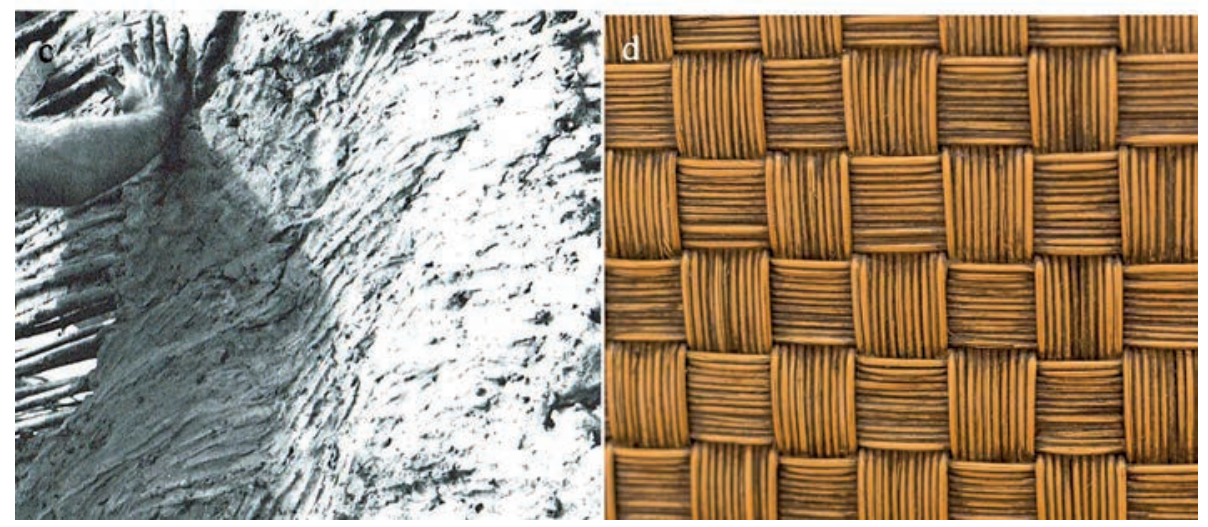

FIG. 5. a) cara externa de un resto constructivo de barro de Les Moreres con huellas de alisado manual; b) cara interna de la misma pieza con impronta de estera; c) alisado de la superficie externa de barro de un alzado (Pétrequin, 1991: 56); d) estera vegetal con trama en damero (según Apuntes. Revista Digital de Arquitectura). 

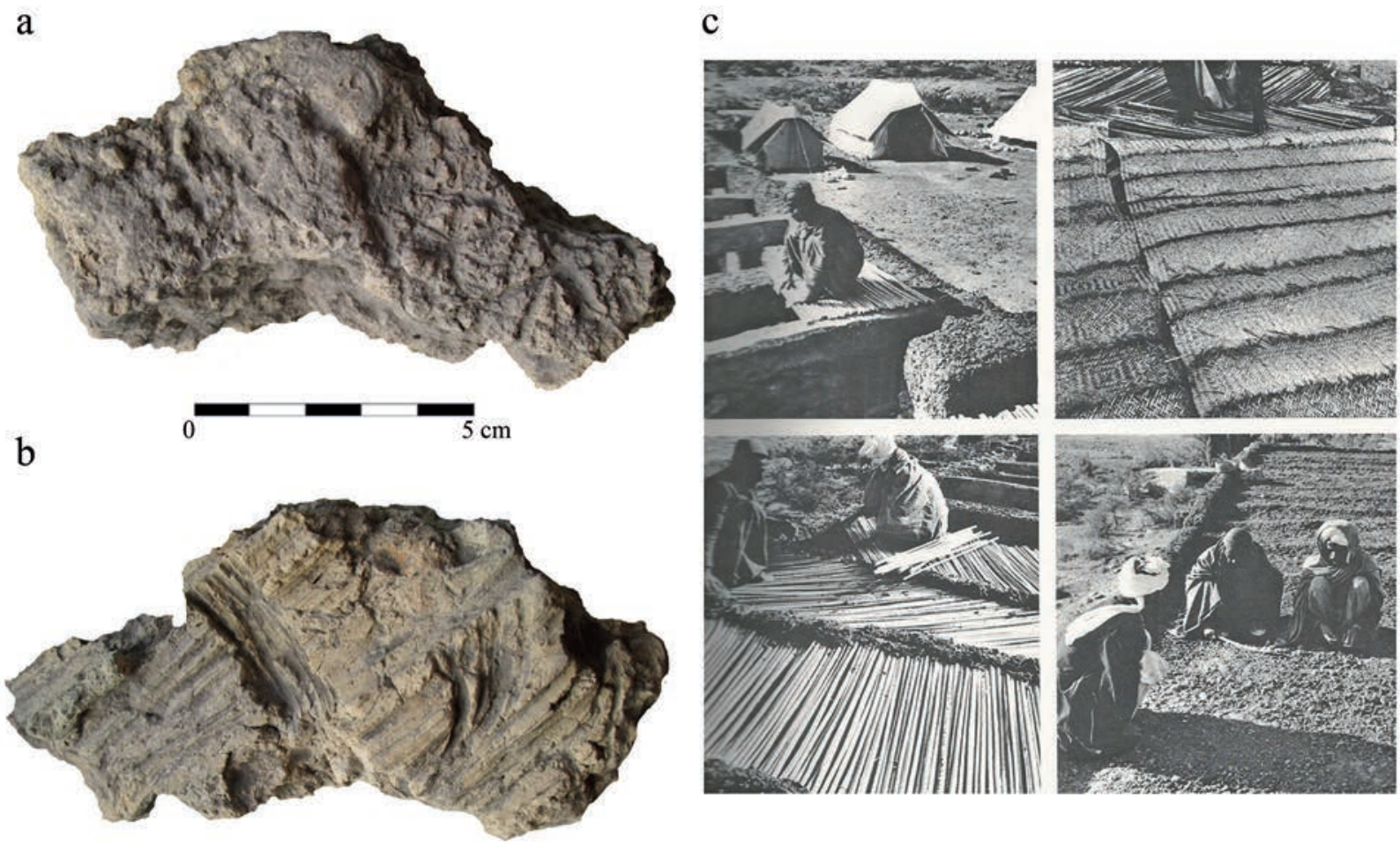

Fig. 6. a) cara con huellas vegetales de pequeña talla de un elemento constructivo de Les Moreres; b) cara contraria del mismo resto, con impronta de estera; c) construcción de cubiertas con varas, esteras y barro en Pakistán (Guidoni, 1977: 11).

Padilla et al., 2017), o en la ocupación de la Edad del Hierro I de Peña Negra (González Prats, 1983; Lorrio et al., 2017) $)^{5}$.

Por los rasgos descritos y la presencia de estas características huellas de alisado manual y de capas superpuestas en las superficies, estos fragmentos constructivos pueden corresponderse con alzados, lo que implicaría el empleo de esteras como parte de los mismos, en el interior de esta parte estructural de las edificaciones calcolíticas de Les Moreres. Como se ha adelantado, estas piezas que asociamos a alzados conservan las huellas de los dedos en las caras externas, con trayectoria posiblemente horizontal. Así, observando la dirección de las improntas conservadas en la cara contraria de las piezas, podemos proponer que la estructura de cañas de los alzados se habría dispuesto, al menos en los tramos en los que se utilizaron las esteras, también en horizontal.

5 También Pastor, op. cit. n. 2: 226, 300, fig. 169a y 450, fig. 298.
El hecho de contar con este indicador que permita plantear la orientación de las improntas vegetales en una parte concreta de la estructura es algo muy poco común en el estudio de restos constructivos de barro. No obstante, no puede descartarse que estas piezas se correspondan con otras partes estructurales, como la cara interna de cubiertas revestidas con barro desde el interior, donde hubieran quedado impresas las huellas de los dedos.

En todo caso, aunque estas piezas con huellas horizontales del alisado con los dedos e improntas de esteras pertenecieran a alzados, las esteras pudieron haberse utilizado también en otras partes de las edificaciones, incluida la cubierta. Algunos de estos fragmentos de Les Moreres, que muestran en una de sus caras el negativo de una estera, presentan en la contraria abundantes huellas vegetales de pequeña talla (Fig. 6a), que pueden asociarse a las techumbres (Belarte, 1999-2000: 70, fig. 3; De Chazelles, 
2003: 49, fig. 2; García López, 2010: 99-101) ${ }^{6}$, en concreto a la parte externa. Por ello, como indica el análisis macroscópico de estos restos, las esteras pudieron haberse empleado también como parte del entrevigado, entre una superficie de cañas y la capa de barro que la cubriría (Fig. 6c), barro sobre el que se dispondría la materia vegetal que habría podido constituir el exterior de la techumbre. En este caso, la estera podría haberse dispuesto con el objetivo de contribuir al soporte de la capa de barro dispuesta sobre las cañas.

A pesar de que las evidencias más claras del uso de esteras como material de construcción, en características y número, han sido identificadas en los restos de barro endurecido analizados de Les Moreres, estas no han sido los únicos indicios documentados que permiten plantear esta práctica.

En el yacimiento de la primera mitad del v milenio a. C. de Los Limoneros II en Elche, Alicante, que se correspondería con un hábitat neolítico disperso al aire libre (Barciela et al., 2014; García Atiénzar et al., 2020: 31), entre el pequeño conjunto de elementos de barro recuperados en 2013, procedentes de deposiciones secundarias en distintas fosas y un foso y entre los que se encontraban piezas de claro carácter constructivo, se halló un resto de barro en el que se observa, de forma nítida y sobre una superficie plana, la impronta de un elemento vegetal entretejido (Fig. 7).

6 También Pastor, op. cit. n. 2: 248, fig. 129. n. ${ }^{\circ}$ ).
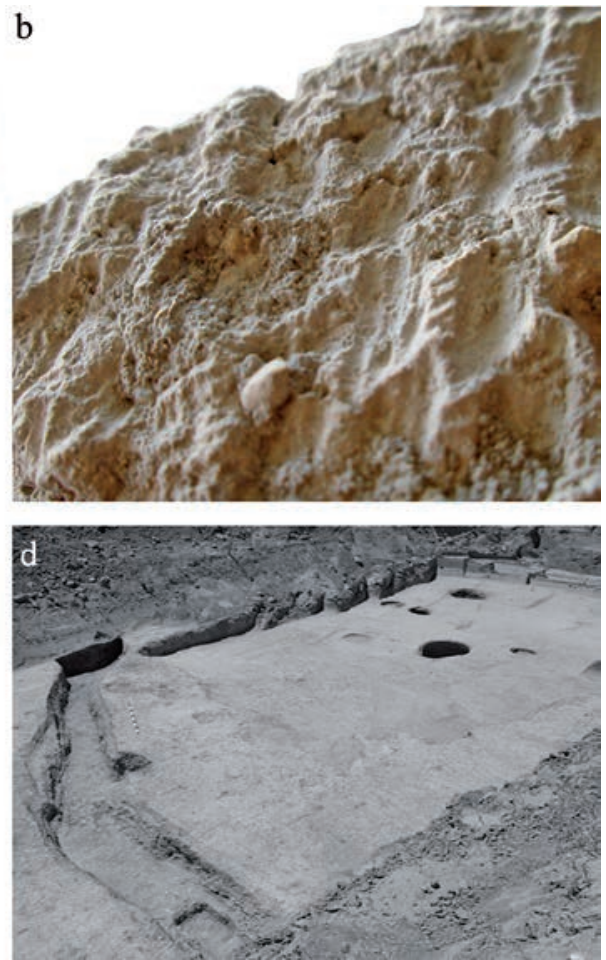

Fig. 7. Asentamiento neolitico de Los Limoneros II (Elche, Alicante): a) resto de barro endurecido con impronta de superficie vegetal entretejida; b) detalle de la impronta; c) diseño esquematizado del entramado, con trama cordada; d) área excavada de cronología neolítica con el foso en primer plano a la izquierda (Barciela et al., 2014: 47, fig. 6,

Este fragmento fue hallado en la uE 1018, en el relleno del foso (Fig. 7d), junto con otros seis restos de barro, dos de ellos con una cara alisada. Presenta una importante consistencia y unas dimensiones de $6,5 \times 4,3 \times 3,4 \mathrm{~cm}$. Este entramado vegetal habría estado compuesto por fibras entretejidas de sección circular y aproximadamente $1 \mathrm{~mm}$ de diámetro (Pastor, 2017: 128). Se correspondería con la denominada trama cordada, mediante la cual dos hebras activas son dispuestas mediante torsión encerrando los elementos pasivos (Kuoni, 1981: 278), dispuestos en paralelo y separados entre sí, perpendiculares a las hebras activas. Esta técnica, habitual en la fabricación de esteras, puede elaborarse dejando espacios abiertos entre las pasadas, como se vería en la impronta de esta pieza. Ejemplos de su uso se encuentran, por ejemplo, entre los materiales de cestería de la Cueva de los Murciélagos (Alfaro, 1980: 
113), así como en los restos de barro epipaleolíticos de Coves de Santa Maira (Aura et al., 2019: fig. 7). Aunque bien puede tratarse de un resto constructivo, por desgracia, este fragmento de barro no cuenta con otros rasgos, como improntas de cańas, de madera o capas de revestimiento, que permitan acreditar con mayor probabilidad su pertenencia a una edificación.

Del mismo modo, otra impronta de superficie de entramado vegetal ha sido documentada sobre un resto de barro endurecido del enclave argárico de Caramoro I en Elche, Alicante (González Prats y Ruiz Segura, 1995; Jover et al., 2019, 2020) (Fig. 8a), construido a inicios del II milenio a. C. Esta pieza fue recuperada en 1989 en el Espacio A, un edificio de planta rectangular y un extremo absidal que articularía la circulación en el asentamiento y donde se encontraría el principal acceso. Se trata de una construcción con gruesos zócalos de mampostería de piedra y un banco corrido levantado también con esta técnica (Fig. 8b). En este espacio se recuperó durante las excavaciones llevadas a cabo en la década de 1980, así como en las recientes, sobre todo en 2016, un buen grupo de restos de barro endurecido estabilizados con materia vegetal. Entre ellos hay elementos asociados a la técnica del bajareque, con improntas de cañas y carrizo, así como de cuerdas trenzadas. Asimismo, en este enclave son significativos los restos constructivos de tierra asociados a la técnica del amasado en forma de bolas y bloques. El hallazgo de improntas de cuerdas en los bloques, que fueron dispuestos unos sobre otros en estado aún húmedo, permite plantear la posibilidad de que estas cuerdas hubieran tenido un uso constructivo, quizá para reforzar la consistencia de la estructura, fomentando una mayor adhesión entre estas unidades (Pastor et al., 2018: 89).

Este resto con la impresión de una estera, con unas dimensiones de $8,5 \times 9 \times 5 \mathrm{~cm}$, se encuentra considerablemente endurecido y conserva huellas del uso de estabilizante vegetal en la mezcla de barro. En su etiquetado se indicó 'suelo de la casa'. La impronta ocupa una superficie reducida e irregular, dificultando la identificación del tipo de entramado.

Por otro lado, en el asentamiento de la Edad del Bronce de Cabezo del Polovar en Villena, Alicante (Jover et al., 2016), en el estrato de derrumbe UE 3007 del Ambiente 2 de su cresta central se recuperó en 2014 un resto de barro de escasa consistencia con el negativo de un entramado vegetal en una de sus caras (Fig. 9). En este mismo nivel de derrumbe se hallaron otros 17 restos de barro, algunos con caras
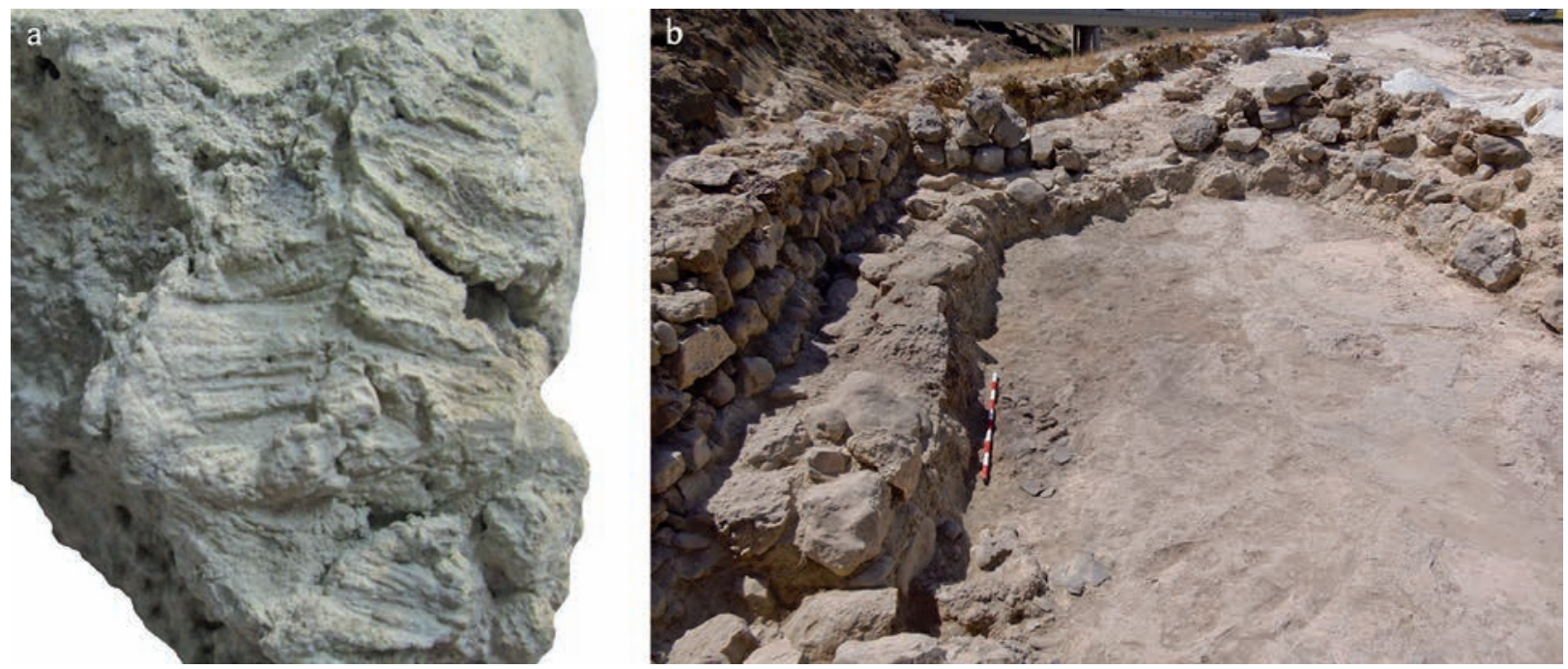

FIG. 8. Enclave de la Edad del Bronce argárico de Caramoro I (Elche, Alicante): a) detalle de la impronta de una superficie vegetal entretejida en un resto de barro endurecido; b) vista del Espacio A desde el acceso (fotografía de F. J. Jover). 
a

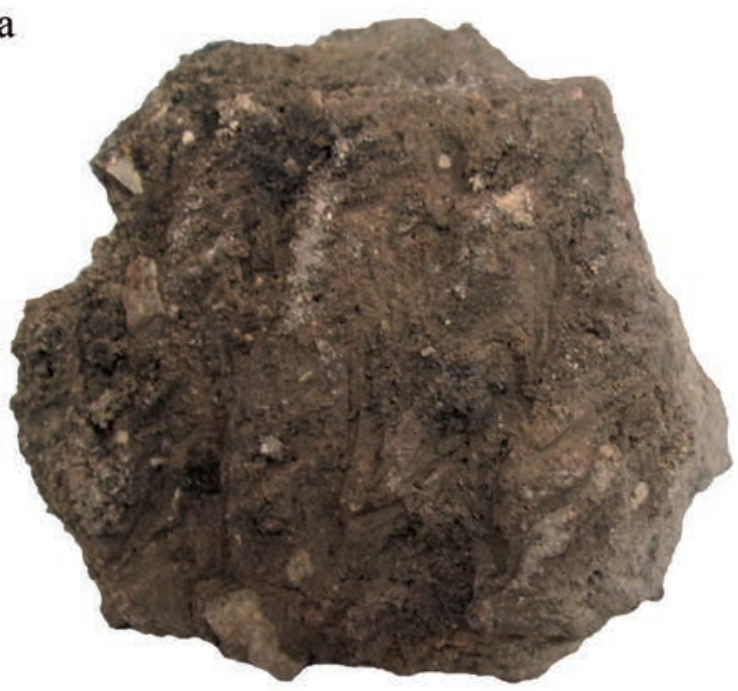

b

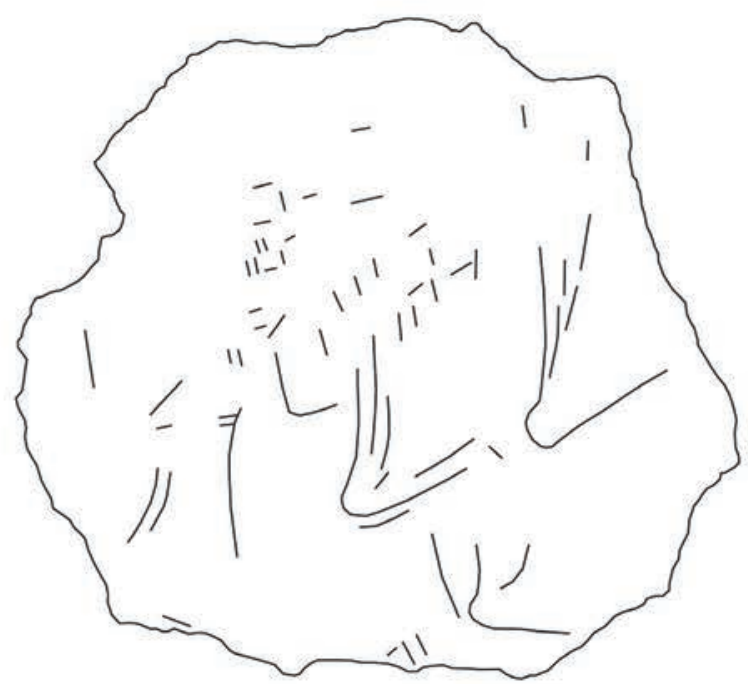

c

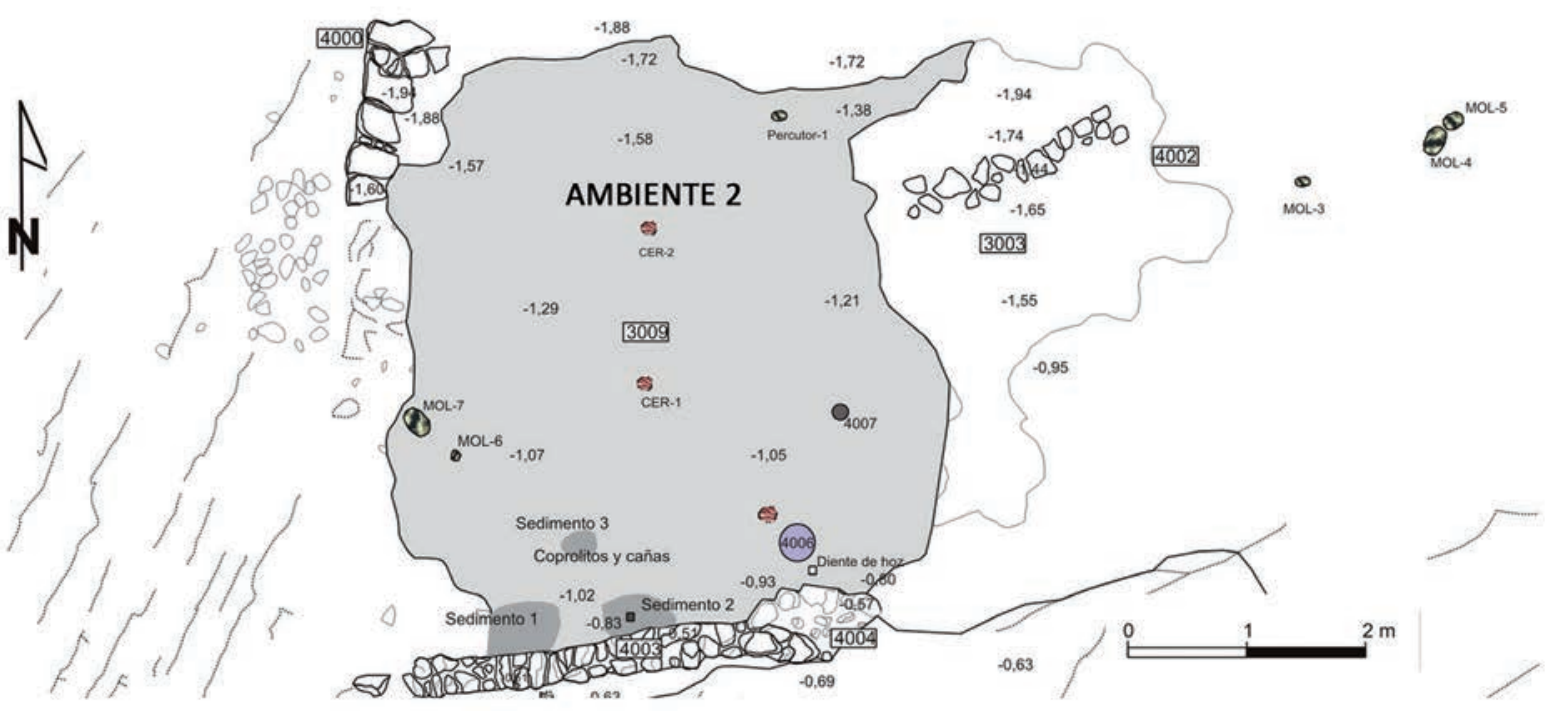

Fig. 9. a) negativo de entramado vegetal en un fragmento de barro del asentamiento de la Edad del Bronce de Cabezo del Polovar (Villena, Alicante); en la parte superior de la imagen, impronta de sección circular en uno de los laterales del bloque; b) diseño esquematizado del entramado, que se correspondería con trama en sargas; c) Ambiente 2 del área central de Cabezo del Polovar, la estancia donde fue recuperado este elemento (a partir de Jover et al., 2016: 55, fig. 11).

alisadas o con improntas de carrizo y cańas, que podemos asociar a la construcción con bajareque.

Con una extensión conservada de $8,5 \times 7,5 \mathrm{~cm}$, este elemento de barro muestra también en uno de los laterales una impronta constructiva, de sección circular, $1,5 \mathrm{~cm}$ de diámetro aproximado y de 3 $\mathrm{cm}$ de longitud. La presencia de esta impronta, que pudo pertenecer a una caña o vara, apunta a que la superficie entretejida pueda corresponderse con una estera utilizada para edificar, perteneciente a una parte estructural al igual que el elemento al que perteneciera la impronta y habiendo sido ambos cubiertos con barro. Aunque la escasa consistencia del elemento de barro no permite observar la trama con demasiada nitidez, habría podido ser realizada con entramado cruzado o en sargas 
(Alfaro, 1980; 1984: 96, 155), al igual que las documentadas, por ejemplo, sobre restos de barro ibéricos del Cerro de la Cruz en Almedinilla, Córdoba (Moralejo et al., 2015: figs. 7 y 28).

Contamos con otra impronta de entramado vegetal en un resto de barro del asentamiento de la Edad del Bronce de Terlinques en Villena, Alicante (Jover y López Padilla, 2016) (Fig. 10), ubicado en un cerro no muy alejado del yacimiento anterior. Fue hallada en 2005 en el interior de la Unidad Habitacional 1, en la UE 1006 de derrumbe, asociada a la Fase I del enclave, estrato en el que se recuperó una treintena de fragmentos de barro, con superficies alisadas y también evidencias de bajareque, con improntas de cañas. La Unidad Habitacional 1 , destruida por un incendio, es una edificación
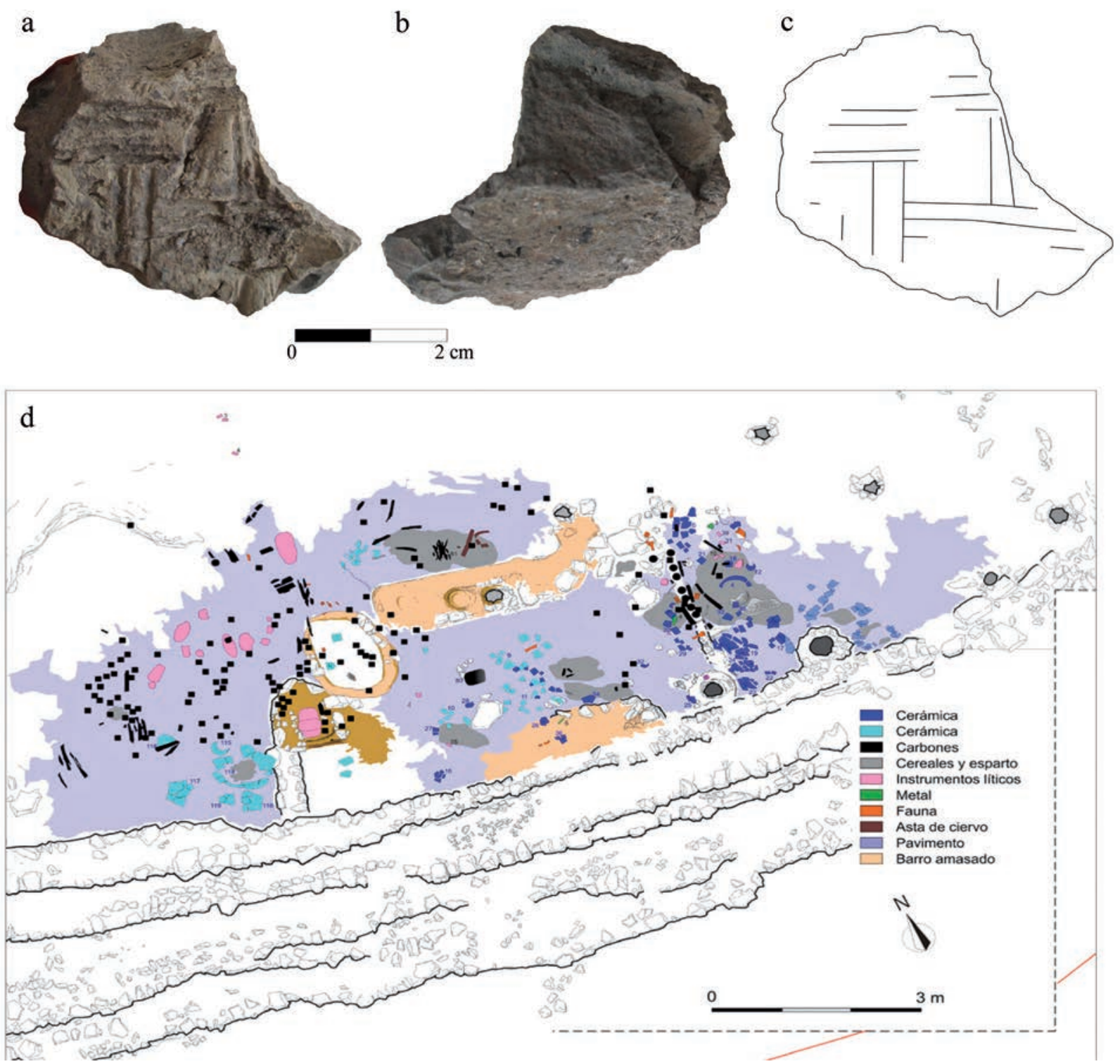

Fig. 10. Elementos de barro endurecido de la Edad del Bronce recuperados en Terlinques (Villena, Alicante): a) impronta de entramado vegetal; b) cara opuesta del mismo; c) diseño esquematizado del entramado, que se correspondería con trama en sargas; d) plano de la Unidad Habitacional 1 de Terlinques (Jover y López Padilla, 2016: 433, fig. 5). 

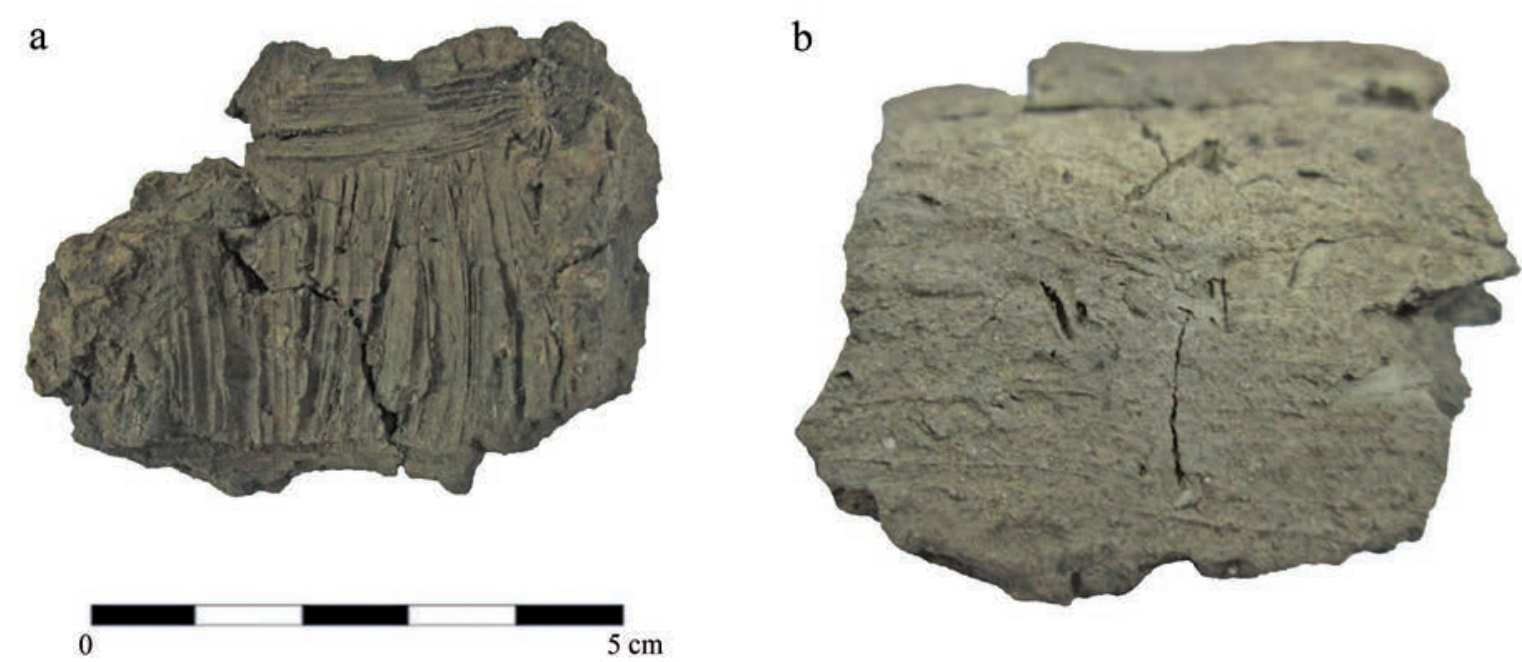

c

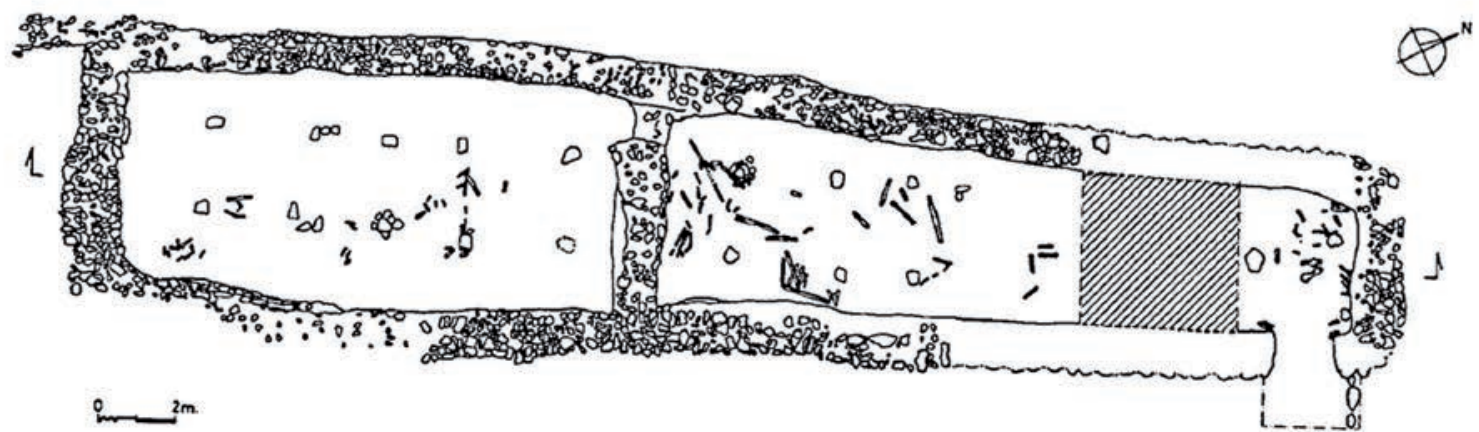

Fig. 11. Asentamiento de la Edad del Bronce de la Lloma de Betxi, en Paterna, Valencia: a) impronta de superficie vegetal entretejida en la cara interna de un resto de barro endurecido; b) vista de la cara externa, alisada y curva, con huellas negativas del empleo de estabilizante vegetal; c) planta del gran edificio excavado en la Lloma de Betxí (a partir de De Pedro, 1998: 49, fig. 18).

amplia y de planta alargada con zócalos de piedra de doble paramento y postes de madera que contribuirían a sustentar la techumbre, que fue edificada empleando diferentes especies vegetales manteadas con barro, incluido esparto picado, cuyos restos fueron hallados entre los travesaños. Asimismo, en ella se recuperaron los restos de un tabique de $1,5 \mathrm{~m}$ de longitud, compuesto por ocho troncos alineados, revestidos con barro (Jover y López Padilla, 2013: 158; 2016: 434).

En este caso, se trata de una pieza endurecida y de reducidas dimensiones, $3,7 \times 2,5 \times 2,3 \mathrm{~cm}$, que muestra huellas negativas en su matriz del empleo de estabilizante vegetal. Aun teniendo en cuenta la escasa extensión de esta superficie, que no permite observar la trama con mayor claridad, podría corresponderse con un entramado en sargas.

Por último, también en cronologías de la Edad del Bronce, contamos con un fragmento de barro con impronta de una probable estera hallado en la Lloma de Betxí en Paterna, Valencia (De Pedro, 1990, 1998) (Fig. 11a). Este asentamiento de la primera mitad del II milenio a. C. cuenta con una gran construcción de planta alargada, dividida en dos estancias. Sus alzados son de mampostería y habría tenido una techumbre de materia vegetal y barro (De 
Pedro, 1998: 170 y 175). En la techumbre la materia vegetal se dispondría sobre vigas y travesaños de madera sujetos con cuerdas de esparto (De Pedro, 1990: 339). En el interior de estos espacios se han localizado dos hileras de piedras planas, asociadas a maderos carbonizados, que habrían constituido bases para postes (Fig. 11c). En sus contextos de derrumbe se recuperaron fragmentos de barro con improntas de cañas y ramaje, también con caras planas revestidas (De Pedro, 1998: 47, 178)7 , asociados a la construcción con bajareque.

Este elemento, de 4,8 x 3,4 x 1,1 cm, presenta la impronta de entramado vegetal en su cara interna, cóncava, mientras que en la externa se observa una superficie alisada, con huellas derivadas de este tratamiento y evidencias del empleo de estabilizantes vegetales en la elaboración de la mezcla de barro. Estos rasgos permiten plantear que la estera se encontraba integrada en un elemento estructural, que podría pertenecer a una edificación, siendo cubierta con barro modelado en una terminación curva y posteriormente alisado (Fig. 11b). A pesar de que sus dimensiones son también reducidas, parece tratarse de un entramado en damero.

\section{Discusión}

Aunque no son habitualmente consideradas como material de construcción, las esteras vegetales se han utilizado para edificar en muchas sociedades del planeta, aplicadas en distintas partes estructurales. Así, son diversos los ejemplos etnográficos y etnoarqueológicos que muestran el empleo de esteras con diferentes usos en el ámbito de la arquitectura.

$\mathrm{Su}$ empleo como material principal en alzados se documenta etnográficamente en numerosos países del SE asiático, como Myanmar, así como en India y Nepal, y en países africanos como Etiopía (Oliver, 1971, 1987; Steen et al., 2003: 136, 147). En algunos casos, los vegetales dispuestos de forma entrelazada, del mismo modo en el que se pueden realizar las esteras, son el material constructivo

7 Pastor, op. cit. n. 2: 407. principal para levantar toda la estructura (Oliver, 1971: 117-120). Por otra parte, su utilización en las cubiertas es común en varios países africanos (Lander y Niermann, 1980: 30; Frobenius-Institut, 1990: lám. 58) y también en territorios del Próximo Oriente (Lloyd, 1963: fig. 15; Aurenche, 1977: 24; Guidoni, 1977: 11) y se documenta desde la Prehistoria. Mellaart (1967: 56) lo mencionaba, basándose en paralelos etnográficos, en referencia a las cubiertas neolíticas de Çatalhöyük, que habrían sido elaboradas con cańas cubiertas de barro y que contendrían esteras en su superficie interna. A partir de excavaciones más recientes en este asentamiento, la presencia de esteras en las cubiertas ha sido asimismo considerada (Matthews, 2005: 134; Stevanović, 2013: 99). También se ha registrado el uso de esteras en la Antigüedad en regiones del Próximo Oriente y Egipto, integradas entre las hiladas de los alzados de adobe (Aurenche, 1977: 124; Spencer, 1979: fig. 47a), con el objetivo de reforzar la edificación (McIntosh, 1974: 163), asentando la horizontalidad de las hiladas.

Las finalidades propuestas para la aplicación de las esteras como parte de las estructuras edificadas son diversas y pueden ser múltiples. Trabajos experimentales sobre construcciones de la Edad del Hierro en Dinamarca han planteado el empleo de esteras en la superficie interna de los alzados construidos con la técnica del bajareque, argumentando su función como aislante térmico adicional (Rasmussen, 2007: 160). El añadido de fibras vegetales sueltas a las partes constructivas también puede estar destinado a facilitar la adhesión de los revestimientos, lo que también puede realizarse mediante el añadido de las fibras en forma de cordaje (Navarro y Navarro, 2016: 60, fig. 36; Knoll et al., 2019: $37)^{8}$. En general, las fibras vegetales o animales, como plantas, lana, textiles o crines, introducidas en el interior de alzados, techumbres o forjados de segundos pisos, pueden actuar como ligantes, aislantes o introducirse en el entrevigado para contribuir a sostener el barro. Este uso de las esteras vegetales puede observarse hoy en la arquitectura tradicional

8 Ibidem: 104, fig. 35. 
en la Península Ibérica o en Francia (Kuoni, 1981: 254; Milcent, 2007: 190, fig. 14).

Entre las evidencias presentadas en este artículo del uso de superficies vegetales entretejidas empleadas como material de construcción, recuperadas en distintos asentamientos de la Prehistoria Reciente del SE de la Península Ibérica, destaca el conjunto de restos de barro endurecido de Les Moreres. En este enclave calcolítico, las improntas de este tipo que pueden considerarse como de esteras y que se vinculan a partes arquitectónicas son de excepcional relevancia, por su número y por lo informativo de sus rasgos, en asociación directa con improntas de bajareque y otros indicadores que permiten inferir el origen constructivo de estos fragmentos. En este asentamiento se constata así el empleo de esteras para construir, posiblemente en diferentes partes de las edificaciones, integradas en la puesta en obra de la técnica constructiva del bajareque. A partir de las evidencias mostradas, planteamos que estas esteras se utilizaron posiblemente en los alzados, entre los elementos vegetales de sección circular, cañas o varas, y el barro, alisado con posterioridad. Sin embargo, no puede descartarse que las esteras se hubieran aplicado también en las techumbres, de lo que se han observado algunos indicios. Las esteras de Les Moreres se habrían fabricado posiblemente con esparto, planta abundante y con una gran tradición histórica en la zona, y en crudo, conservando las fibras su sección circular.

No obstante, como ha sido expuesto, el hallazgo de improntas de superficies entretejidas de origen vegetal no es tan excepcional respecto al resto de conjuntos de materiales constructivos de barro analizados de la Prehistoria Reciente del se peninsular?. Tanto en el yacimiento neolítico de Los Limoneros II como en los de la Edad del Bronce de Caramoro I, Terlinques, Cabezo del Polovar y la Lloma de Betxí se han documentado fragmentos con la impronta de una superficie vegetal entretejida. Estas superficies se encuentran en restos de barro endurecido en los que se observan huellas de estabilizantes vegetales y que en parte contaban con improntas constructivas

9 Pastor, op. cit. n. 2. que pueden vincularse a la técnica del bajareque, con varas, cañas y carrizo o con caras alisadas. Estos son indicadores que permiten plantear que los negativos de esteras se generaran por el uso de estas superficies como material empleado para edificar, al menos, en una parte de estos casos y quizá también en los restantes. Las técnicas de fabricación a las que se corresponderían serían tres diferentes, observadas en los distintos enclaves: trama cordada en el caso más antiguo, el resto de la primera mitad del v milenio a. C. de Los Limoneros II; de tipo liso o en damero en las evidencias calcolíticas de Les Moreres y posiblemente en la de la Edad del Bronce de la Lloma de Betxí; y, por último, entramado en sargas en los asentamientos también de la Edad del Bronce de Cabezo del Polovar y posiblemente en el ejemplar de Terlinques.

Con la salvedad del ejemplo procedente del conjunto de materiales de barro neolíticos de Los Limoneros II, escaso en número y recuperado en deposiciones secundarias, los fragmentos presentados con improntas de estera proceden de espacios de hábitat y actividad de cronologías entre la segunda mitad del III milenio y la primera mitad del II milenio a. C., en construcciones en las que se constata el empleo de cuerdas trenzadas de fibras vegetales, así como la edificación con bajareque. La estructura vegetal y de madera que constituye el armazón de bajareque de alzados, techumbres y otras partes constructivas presenta formas de puesta en obra similares a las de las fibras que se entrelazan en las técnicas de cestería y esterería, pudiendo considerarse que se trata de un mismo concepto de disposición de la materia vegetal para generar superficies y elementos.

En este conjunto de casos considerados, las fibras y los tallos vegetales, como el esparto, se utilizaron ańadidos a la mezcla de barro o a otra materia vegetal que puede conformar las cubiertas, así como en el cordaje para unir diversos componentes constructivos entre sí. En el enclave de Caramoro I, se ha planteado la posibilidad de que las cuerdas se hubieran integrado intencionalmente junto con los bloques de barro amasado, quizá para incrementar la unión entre las partes y la resistencia de la estructura. Por su parte, en Terlinques fueron 
documentados restos de esparto picado entre los maderos de la techumbre.

Todo ello muestra un panorama constructivo caracterizado por el uso conjunto en la conformación de las estructuras de la tierra, la madera y la materia vegetal de mayor o menor diámetro, varas, cañas, tallos y fibras, también en forma de elementos previamente elaborados con ellas, no solo en lo que se refiere al cordaje, sino también mediante esteras. Está por determinar si estas fueron fabricadas para ese propósito o si se trata de superficies vegetales a las que se dio un nuevo uso, en el marco de las habituales prácticas de reutilización de materiales en la arquitectura durante la Prehistoria Reciente (Pastor, 2020), constatándose el reempleo también de elementos que no habían sido producidos para construir con ellos, como ocurre en otros muchos contextos temporales y geográficos.

\section{Consideraciones finales}

El estudio sistemático de restos constructivos de barro endurecido de diferentes asentamientos y diversas cronologías del se de la Península Ibérica ha sacado a la luz el uso en las edificaciones de un elemento que no es considerado habitualmente como material constructivo, pero que las evidencias arqueológicas mostradas aquí hacen posible que comience a considerarse como tal. Este empleo se habría practicado, al menos, en una parte de los asentamientos de la Prehistoria Reciente del SE peninsular, bien por sus propiedades aislantes, para contribuir al sostenimiento de otros materiales constructivos como la tierra, para mejorar la adherencia de los revestimientos exteriores o por otras razones.

Aunque las evidencias disponibles mostradas en este texto son todavía puntuales y parciales para plantear el desarrollo de este fenómeno con una mayor perspectiva histórica, con este trabajo aspiramos a ofrecer un primer acercamiento. Consideramos que la utilización de esteras o de elementos de cestería para edificar pudo haber sido algo relativamente habitual y practicado en distintas cronologías, quizá

Ediciones Universidad de Salamanca / @థ®ఠ a lo largo del espectro cronológico de la Prehistoria Reciente y la Protohistoria e, incluso, antes de los inicios del Neolítico. Como han mostrado los interesantísimos hallazgos de restos de barro con improntas de Coves de Santa Maira (Aura et al., 2019), la elaboración de elementos de esterería o cestería y su empleo junto con mezclas de barro preparadas con estabilizantes vegetales no son prácticas ausentes con anterioridad a la neolitización.

Para que pueda avanzarse en el conocimiento del uso de las esteras también como material constructivo es imprescindible considerar esta posibilidad durante los procesos de excavación y a la hora de documentar e interpretar sus evidencias en los contextos arqueológicos, así como en el estudio de los restos de las mismas que hayan podido preservarse y de las improntas en fragmentos de barro endurecido. Solo la continuidad de los estudios sobre esta materia permitirá determinar el grado de utilización de estos materiales, su localización y funcionalidad en las edificaciones y plantear hipótesis sobre la distribución territorial y cronológica de esta práctica.

\section{Bibliografía}

Agorsah, K. (1985): "Archaeological implications of traditional house construction among the Nchmuru of Northern Ghana", Current Anthropology, 26 (1), pp. 103-115.

Alfaro, C. (1980): "Estudio de los materiales de cestería procedentes de la cueva de Los Murciélagos (Albuñol, Granada)", Trabajos de Prehistoria, 37, pp. 109145.

Alfaro, C. (1984): Tejido y cestería en la Peninsula Ibérica: Historia de su técnica e industria desde la Prehistoria hasta la Romanización. Bibliotheca Praehistorica Hispana, Xxi. Madrid: csic.

Aura, J. E.; Pérez-JordÀ, G.; Carrión, Y.; Seguí, J. R.; Jordá, J. F.; Miret i Estruch, C. y Verdasco, C. (2019): "Cordage, basketry and containers at the Pleistocene-Holocene boundary in southwest Europe. Evidence from Coves de Santa Maira (Valencian region, Spain)", Vegetation History and Archaeobotany. https://doi.org/10.1007/s00334-019-00758-x, https://link.springer.com/article/10.1007\%2Fs00334-019-00758-x 
Aurenche, O. (1977): Dictionnaire illustré multilingue de l'architecture du Proche Orient Ancien. Collection de la Maison de L'Orient Méditerranéen Ancien, 3. Lyon.

Ayala, M. M. (2001): "La Edad de Bronce en la región de Murcia”. En Hernández, M. S.: ... Y acumularon tesoros. Mil años de historia en nuestras tierras. Alicante: CAM, pp. 151-161.

Ayala, M. M. y Jiménez, S. (2007): "Útiles de esparto en la Prehistoria Reciente: evidencias arqueológicas". En Historia y sociabilidad: homenaje a la profesora $M$. C. Melendreras Gimeno. Murcia: Univ. de Murcia, pp. 171-196.

Barciela, V.; García Atiénzar, G. y López Seguí, E. (2014): "El yacimiento prehistórico de Los Limoneros iI (Elche)". En Jover, F. J.; Torregrosa, P. y García Atiénzar, G. (eds.): El Neolítico en el Bajo Vinalopó (Alicante, España). BAR Intern. Ser., 2646. Oxford: Archaeopress, pp. 45-48.

Belarte, M. C. (1999-2000): "Sobre el uso del barro en la protohistoria del Bajo Aragón: estudio de materiales conservados en el Museo de Cataluña-Barcelona”, Kalathos, 18-19, pp. 65-93.

Belmonte, D.; Thierry, P.; López, V. y Satorre, A. (2017): "Las primeras evidencias del empleo del esparto en Crevillent". En Crevillent, l'etnografia d'un poble. Quaderns d'Antropologia-Etnografia-Història. Crevillente: Ayto. de Crevillente, vol. 3, pp. 223262.

Bosch, A.; Chinchilla, J. y Tarrús, J. (1999): "La Draga, un poblado del Neolítico Antiguo en el lago de Banyoles (Girona, Catalunya)". En 11 Congrés del Neolitic a la Península Iberica. Saguntum Extra, 2. Valencia, pp. 315-321.

Bruno, P.; Faria, P.; Candeias, A. y Mirâo, J. (2010): "Earth mortars use on prehistoric habitat structures in Southern Portugal. Case studies", Journal of Iberian Archaeology, 13, pp. 51-67.

Cameron, J. (2017): "Matting Impressions from Lo Gach: Materiality at Floor Level". En Piper, P. J.; Matsumura, H. y Bulbeck, D. (eds.): New Perspectives in Southeast Asian and Pacific Prehistory. Canberra: The Australian National University, pp. 357-367.

Cavanilles, A. J. (1795): Observaciones sobre la historia natural, geografía, agricultura, población y frutos del Reyno de Valencia. Madrid: Imprenta Real.

Contreras, F. (2009): "Los grupos argáricos de la Alta Andalucía: patrones de asentamiento y urbanismo.
El poblado de Peñalosa (Baños de la Encina, Jaén)", Anales de Prehistoria y Arqueología, 25-26, pp. 49-76.

De Chazelles, C. A. (2003): "Les torchis, la toiture en chaume, terre et lauzes". En Guilaine, J. y Escalon, G. (dirs.): Les Vautes (Saint-Gély-du-Fesc, Hérault) et la fin du Néolithique en Languedoc oriental. Toulouse: Archives d'Écologie Préhistorique, pp. 47-53.

De Góngora, M. (1868): Antigüedades prehistóricas de Andalucía. Madrid.

De Pedro, M. J. (1990): “La Lloma de Betxí, Paterna: datos sobre técnicas de construcción en la Edad de Bronce", Archivo de Prehistoria Levantina, 20, pp. 327-350.

De Pedro, M. J. (1998): La Lloma de Betxí (Paterna, Valencia). Un poblado de la Edad del Bronce. Trabajos Varios del sip, 94. Valencia: Diput. de Valencia.

Elster, E. (2003): "Tools of the Spinner, Weaver, and Mat Maker". En Elster, E. y Renfrew, C. (eds.): Prehistoric Sitagroi: Excavations in Northeast Greece, 1968-1970. Volume 2: The Final Report. Monumenta Archaeologica, 20. Los Ángeles: Cotsen Institute of Archaeology, pp. 229-251.

Fajardo, J.; Verde, A.; Rivera, D.; Obón, C. y Leopold, S. (2015): "Traditional Craft Techniques of Esparto Grass (Stipa tenacissima L.) in Spain”, Economic Botany, 69 (4), pp. 370-376.

Frobenius-Institut (1990): Aus Erde geformt. Lehmbauten in West- und Nordafrika. Maguncia: Verlag Philipp von Zabern.

García Atiénzar, G.; Barciela, V.; Martínez Monleón, S.; Jover, F. J.; Molina, F. J.; Tormo, C.; Pastor, M.; Del Pino, M.; De Miguel, M. P.; López, E.; Torregrosa, P.; Ferrer, C.; Pérez, G.; Carrión, Y.; López, J. A. y Sirvent, L. M. (2020): "El asentamiento neolítico de Limoneros (Elche, Alicante)", Complutum, 31 (1), pp. 25-48.

García Atiénzar, G. y Busquier, J. D. (coords.) (2020): El poblado calcolitico de Vilches IV (Torre Uchea, Hellin, Albacete). Un asentamiento del III milenio a. C. en la Submeseta sur. Alicante: Univ. de Alicante.

García Atiénzar, G.; Busquier, J. D.; Mataix, J. J.; Cañizares, F.; Domene, P.; Carrión, Y.; Tormo, C.; Pérez-Jordà, G.; Jover, F. J.; López Padilla, J. A.; Barciela, V.; Montero, I. y Soriano, I. (2016): "El poblado de Vilches IV: un asentamiento calcolítico en altura en el campo de Hellín (Albacete)". En Gamo, B. y Sanz, R. (coords.): Actas I Reunión Científica de Arqueología de Albacete. Albacete: 
Inst. de Estudios Albacetenses 'Don Juan Manuel', pp. 313-329.

García López, E. (2010): "Restes de fang neolítiques. Morfologia e interpretació dels elements documentats a la mina 84 de Gavà", Rubricatum, 4, pp. 97108.

García López, E. y Lara, C. (1999): "La construcció en terra”. En González Marcén, P.; Martín CóLliga, A. y Mora, R.: Can Roqueta. Un establiment pagès prehistòric i medieval. Excavacions Arqueològiques a Catalunya, 16. Barcelona: Generalitat de Catalunya, pp. 193-204.

Gómez Puche, M. (2004): "Los elementos de barro cocido”. En Gómez Puche, M.; Diez, A.; Orozco, T.; Pascual, J. L.; López Gila, M. D.; Carrión, Y.; Verdasco, C.; García Borja, P.; García Puchol, O. y McClure, S. B.: "El yacimiento de Colata (Montaverner, Valencia) y los 'poblados de silos' del IV milenio en las comarcas centro-meridionales del País Valenciano", Recerques del Museu d'Alcoi, 13, pp. 83-86.

González Prats, A. (1983): Estudio arqueológico del poblamiento antiguo de la Sierra de Crevillente (Alicante). Alicante: Anejo Lucentum, 1. Alicante: Univ. de Alicante.

González Prats, A. (1984): "El poblado calcolítico de Les Moreres en la Sierra de Crevillente, Alicante". En El Eneolitico en el País Valenciano. Actas Coloquio, 1984. Alcoy, pp. 89-100.

González Prats, A. (1986): “Les Moreres”. En Arqueología en Alicante 1976-1986. Alicante: Inst. de Estudios J. Gil-Albert, p. 121.

González Prats, A. y Ruiz Segura, E. (1991-1992): "Nuevos datos sobre el poblado calcolítico de Les Moreres, Crevillente (Alicante). Campañas 19881993", Anales de Prehistoria y Arqueología de la Univ. de Murcia, 7-8, pp. 17-20.

González Prats, A. y Ruiz Segura, E. (1995): “Urbanismo defensivo de la Edad del Bronce en el Bajo Vinalopó. La fortificación argárica de Caramoro I (Elche, Alicante)". En Estudios de vida urbana, pp. 85-105.

Guerrero, L. F. (2007): "Arquitectura en tierra. Hacia la recuperación de una cultura constructiva", Apuntes, 2 (2), pp. 182-201.

Guerrero, L. F. (2017): "Pasado y porvenir de la construcción con bajareque", Gremium, 4 (8), pp. 69-80.

Guidoni, E. (1977): Arquitectura primitiva. Madrid: Aguilar.
Hernández, M. S.; García Atiénzar, G. y Barciela, V. (2016): Cabezo Redondo (Villena, Alicante). Alicante: Univ. de Alicante.

Jover, F. J. y López Padilla, J. A. (2013): "La producción textil durante la Edad del Bronce en el cuadrante suroriental de la Península Ibérica: materias primas, productos, instrumentos y procesos de trabajo", Zephyrus, Lxxi, pp. 149-171.

Jover, F. J. y López Padilla, J. A. (2016): "Nuevas bases para el estudio de las comunidades campesinas de la Edad del Bronce en el Levante peninsular: el asentamiento de Terlinques (Villena, Alicante)". En Del Neolitic a l'Edat del Bronze en el Mediterrani occidental. Estudis en homenatge a Bernat Marti Oliver. Serie de Trabajos Varios del sip, 119. Valencia: Diput. de Valencia, pp. 427-449.

Jover, F. J.; Martínez Monleón, S. y López Padilla, J. A. (2020): La vida en la frontera: el asentamiento argárico de Caramoro I (Elche, Alicante). Valencia: Diput. de Valencia.

Jover, F. J.; Martínez Monleón, S.; Pastor, M.; Poveda, E. y López Padilla, J. A. (2016): "Los asentamientos de pequeño tamaño de la Edad del Bronce en tierras valencianas: A propósito del Cabezo del Polovar (Villena, Alicante)", Recerques del Museu d'Alcoi, 25, pp. 47-68.

Jover, F. J.; Pastor, M.; Basso, R.; Martínez Monleón, S. y López Padilla, J. A. (2019): "Secuencia de ocupación y desarrollo constructivo del asentamiento de Caramoro I (Elche, Alicante): aportaciones a la arquitectura argárica", Arqueología de la Arquitectura, 16, e083. https://doi.org/10.3989/arq. arqt.2019.005, http://arqarqt.revistas.csic.es/index. php/arqarqt/article/view/239

Kelly, R. L.; Poyer, L. y Tucker, B. (2005): “An Ethnoarchaeological Study of Mobility, Architectural Investment and Food Sharing among Madagascar's Mikea", American Anthropologist, 107 (3), pp. 403416.

Knoll, F. y Klamm, M. (2015): Baustoff Lehm - seit Jahrtausenden bewährt. Archäologische, historische und rezente Zeugnisse des Lehmbaus. Ein Leitfaden für den Umgang mit Rot- oder Hüttenlehm im archäologischen Befund. Kleine Hefte zur Archäologie in Sachsen-Anhalt, 12. Halle: Landesamt für Denkmalpflege und Archäologie Sachsen-Anhalt.

Knoll, F.; Pastor, M.; De Chazelles, C. A. y Coокe, L. (2019): On cob balls, adobe and daubed straw plaits: A glossary on traditional earth building techniques (walls) in four languages. Tagungen des 
Landesmuseums für Vorgeschichte Halle, Band 18. Halle: Landesamt für Denkmalpflege und Archäologie Sachsen-Anhalt.

Kramer, C. (1982): Village ethnoarchaeology: Rural Iran in archaeological perspective. New York: Academic Press.

Kruger, R. P. (2015): “A Burning Question or Some Half-Baked Ideas: Patterns of Sintered Daub Creation and Dispersal in a Modern Wattle and Daub Structure and Their Implications for Archaeological Interpretation", Journal of Archaeological Method and Theory, 22, pp. 883-912.

Kuoni, B. (1981): Cestería tradicional ibérica. Barcelona: Ed. del Serbal.

Lander, H. y Niermann, M. (1980): Lehm-Architektur in Spanien und Afrika. Königstein im Taunus: Karl Robert Langewiesche Nachfolger.

Lloyd, S. (1963): Mounds of the Near East. Edinburgh: EUP.

López Padilla, J. A.; Jover, F. J.; Martínez Monleón, S.; SÁnchez, A.; Luján, A.; Pastor, M. y Basso, R. (2017): "El Argar alicantino: la Edad del Bronce en el Bajo Segura y Bajo Vinalopó”. En Tomad y bebed. Una copa para un ritual milenario. Al voltant d'una peça. Alicante: MARQ, pp. 65-85.

Lorrio, A.; Trelis, J. y Pernas, S. (2017): "La Penya Negra (Crevillent, Alacant): a la recerca de la ciutat d'Herna", La Rella, 30, pp. 75-116.

Lull, V.; Micó, R.; Rinuete, C. y Risch, R. (2015): La Bastida y Tira del Lienzo (Totana, Murcia). Guías arqueológicas, 1. Murcia: Sociedad para el Desarrollo Rural-ASOME-UAB.

Martínez Carmona, A.; Olcina, M. y Sala, F. (2009): "Nueva lectura de la arquitectura doméstica de la Illeta dels Banyets (el Campello, Alacant)". En BELARTE, M. C. (ed.): L'espai domèstic i l'organització de la societat a la protohistòria de la Mediterrània occidental ( $t^{e r}$ mil.lenni a. C.). Actes IV Reunió Internacional d'Arqueologia de Calafell (Calafel-Tarragona, 2007). Barcelona: Univ. de Barcelona-ICAC, pp. 153-163.

Matthews, W. (1995): "Micromorphological characterisation and interpretation of occupation deposits and microstratigraphic sequences at Abu Salabikh, Iraq". En Barham, T. y Macphail, R. I.: Archaeological sediments and soils. Analysis, interpretation and management. London: Institute of Archaeology, pp. 41-74.

Matthews, W. (2005): "Life-cycle and Life-course of Buildings". En Hodder, I. (ed.): Çatalhöyük Perspectives: themes from the 1995-99 seasons. Ankara:
McDonald Institute for Archaeological Research British Institute of Archaeology at Ankara, pp. 125149.

Matthews, W. (2012): "Defining households: Micro-contextual analysis of Early Neolithic Households in the Zagros, Iran". En PArker, B. J. y Foster, C. P.: New Perspectives on household archaeology. Winona Lake: Eisenbrauns, pp. 183-216.

McIntosh, R. J. (1974): "Archaeology and mud wall decay in a West-African village", World Archaeology, 6, pp. 154-171.

Mellaart, J. (1967): Çatal Hüyük: A Neolithic Town in Anatolia. London: Thames and Hudson.

Milcent, D. (2007): "L'architecture en bauge dans le Nord-Ouest de la Vendée : les bourrines du Marais Breton”. En Guillaud, H.; De Chazelles, C. A. y KLeIn, A. (eds.): Les constructions en terre massive: pisé et bauge. Deuxièmes échanges transdisciplinaires sur les constructions en terre crue, Actes Table Ronde de Villefontaine (Isère, 2005). Montpellier: Éditions de l'Espérou, pp. 181-198.

Moralejo, J.; Kavanagh, E. y Quesada, F. (2015): "Improntas vegetales en arquitectura e improntas de cestería en el yacimiento ibérico del Cerro de la Cruz (Almedinilla, Córdoba)", Lucentum, xxxIv, pp. 119144.

Namdar, D.; Zukerman, A.; Maeir, A. M.; Citron Katz, J.; Cabanes, D.; Trueman, C.; Shahack-Gross, R. y Weiner, S. (2011): "The 9th century A. C. E. destruction layer at Tell es-Safi/Gath, Israel: integrating macro- and microarchaeology", Journal of Archaeological Science, 38, pp. 3471-3482.

Navarro, I. y Navarro, J. J. (2016): Estudio constructivo de las edificaciones rurales de Aspe. Alicante: Inst. de Cultura J. Gil-Albert.

Olcina, M.; Martínez Carmona, A. y Sala, F. (2009): La Illeta dels Banyets (El Campello, Alicante): épocas ibérica y romana I. Historia de la investigación y sintesis de las intervenciones recientes (2000-2003). Alicante: MARQ.

Oliver, P. (1971): Shelter in Africa. London: Barrie and Jenkins.

Oliver, P. (1987): Dwellings. The house across the world. Oxford: Phaidon.

Papí, C. (1992-1994): "Improntas de esterillas de cerámicas del Bronce Final en la Peña Negra (Crevillente, Alicante) -Campañas de 1983 y 1984-", Lucentum, XI, pp. 39-50. 
PAstor, M. (2017): La construcción con tierra en arqueología: teoría, método, técnicas y aplicación. Alicante: Univ. de Alicante.

Pastor, M. (2020): "Reutilización y arquitectura. A propósito del reuso de materiales en la edificación prehistórica de la Península Ibérica", MARQ. Arqueología y Museos, 11, pp. 7-15.

Pastor, M.; Jover, F. J.; Martínez Monleón, S. y López Padilla, J. A. (2018): "La construcción mediante amasado de barro en forma de bolas de Caramoro I (Elche, Alicante): Identificación de una nueva técnica constructiva con tierra en un asentamiento argárico", Cuadernos de Prehistoria y Arqueología de la Univ. Autónoma de Madrid, 44, pp. 81-99.

Perdiguero, P. (2016): “La 'Casa del horno' de la Illeta dels Banyets (El Campello, Alicante): Un taller de esparto en la Contestania ibérica", MARQ. Arqueología y Museos, 7, pp. 41-66.

Pétrequin, P. (dir.) (1991): Construire une maison 3000 ans avant JC. Le lac de Chalain au Néolitique. París: Érrance.

Piqué, R.; Gueye, M.; Hardy, K.; Camara, A. y Dioh, E. (2016): "Not just Fuel: Food and Technology from Trees and Shrubs in Falia, Saloum Delta (Senegal)". En Biagetti, S. y Lugli, F. (eds.): The Intangible Elements of Culture in Ethnoarchaeological Research. New York: Springer, pp. 217-230.

Piqué, R.; Romero, S.; Palomo, A.; Tarrús, J.; Terradas, X. y Bogdanovic, I. (2018): “The production and use of cordage at the early Neolithic site of La Draga (Banyoles, Spain)", Quaternary International, 468, pp. 262-270.

Proterra (2003): Técnicas mixtas de construcción con tierra. Salvador: PROTERRA-HABITED-CYTED.

Rasmussen, M. (2007): Iron Age Houses in Flames. Lejre: Historical-Archaeological Experimental Centre.

Rovira, J. (2006): "Las producciones cerámicas con impronta basal de estera vegetal del Calcolítico Final-Bronce Antiguo/Medio de la Península Ibérica: acerca de la alternancia de influjos y el origen del protourbanismo en la depresión central catalana como modelo de territorio basculante", Quaderns de Prehistòria i Arqueologia de Castelló, 25, pp. 109-137.

SÁnchez Sanz, M. E. (2009): "Fibras vegetales". En PiCazo, J. V. y Rodanés, J. M.: Los poblados del Bronce Final y Primera Edad del Hierro. Cabezo de la Cruz (La Muela, Zaragoza). Zaragoza: Gob. de Aragón, pp. 426-434.

Shaffer, G. (1993): "An archaeomagnetic study of wattle and daub building collapse", Journal of Field Archaeology, 20, pp. 59-75.

Sherard, J. (2009): "Analysis of Daub from Mound v, Moundville: its Role as an Architectural Indicator", Bulletin of the Alabama Museum of Natural History, 27, pp. 29-42.

SPENCER, A. J. (1979): Brick architecture in ancient Egypt. Warminster: Aris and Phillips.

Steen, A.; Steen, B. y Komatsu, E. (2003): Built by hand. Vernacular building around the world. Layton: Gibb Smith Publisher.

Stevanović, M. (2013): "New Discoveries in House Construction at Çatalhöyük". En Hodder, I. (ed.): Substantive technologies at Çatalhöyük: reports from the 2000-2008 seasons. Çatal Research Project, 9. British Institute of Archaeology at Ankara, 48. Ankara: British Institute of Archaeology at Ankara, pp. 97-113.

Van Gijn, A. (1986): "Habitation in Djenné, Mali: Use of space in a West-african town". En VAN DER WAALs, J. D.: Op Zoek Naar Mens En Materiele Cultuur. Groningen: Universiteitsdrukkerij RUG, pp. 163-184.

Viñuales, G. M.; Martins, C. M.; Flores, M. y Silvio, L. (2003): Arquitecturas de tierra en Iberoamérica. Salvador: CYTED-HABITED-Habiterra-Proterra.

Wendrich, W. (2000): “Basketry". En Nicholson, P. T. y Shaw, I.: Ancient Egyptian Materials and Technology. Cambridge: cup, pp. 254-267.

Wendrich, W. (2005): "Çatalhöyük Basketry”. En HoDDER, I. (ed.): Inhabiting Çatalhöyük. Reports from the 1995-1999 seasons. Cambridge: McDonald Institute for Archaeological Research-British Institute of Archaeology at Ankara, pp. 333-338. 